\title{
LA DIVISION TERRITORIAL EN ESPAÑA: 1825-1833
}

\author{
POR \\ MANUEL MORAN
}

SUMARIO: El estado de la cuestión.-Los «arreglos» durante la década final del reinado de Fernando VII._Las ideas de Javier de Burgos sobre división provincial._La culminación de los trabajos después de la muerte del rey.-Epílogo.

\section{LA DIVISION TERRITORIAL EN ESPAÑA: 1825-1833}

La división territorial española ha sido objeto de estudio, particularmente en los últimos años, en un número abundante de publicaciones. Naturalmente, hay razones para ello, puesto que en su doble concepto de reforma administrativa con gran envergadura y de medida encaminada al establecimiento efectivo del orden constitucional, el tema se inscribe en algunos ciclos historiográficos, ya clásicos, como el de la construcción del Estado Liberal sobre la sociedad tradicional, o el de la pervivencia de lo «español» frente a la recepción de ideologías foráneas. Y sin desvincularse por completo de estos planteamientos, la actual revisión en España del concepto de Estado Nacional, ha proporcionado nuevo impulso a estos trabajos. Claro que en parte, esa publicística sería ajena al quehacer del historiador si no mediase un factor especial: el hecho es que a raiz de las excepcionales circunstancias políticas en que fue establecida la división provincial, así como al desconocimiento (y probable pérdida, en buena medida) de la correspondiente documentación, el proceso configurador de las provincias y con él, las motivaciones y repercusiones inmediatas de su planificación, han permanecido oscurecidas hasta no hace mucho tiempo.

Actualmente, este conocimiento podría calificarse quizás, de fragmentario. La investigación histórica ha conseguido describir con rigor algunas etapas integrantes de dicho proceso - los proyectos de 1813 y 1821 especialmente- pero es evidente que existen demasiadas lagunas para poder considerar satisfactorio el estado de la cuestión, con todo lo que eso supone para la estabilidad de las conclusiones generales formuladas. De ahí, que este trabajo consiste en un intento de penetración en tres direcciones sobre las que poco se ha ocupado la historiografía: los trabajos realizados entre 1825 y 1833; las ideas de Javier de Burgos - responsable en última instancia de la definitiva división provincial-sobre el tema, y la culminación del expediente en 1833. Pero antes, como punto de referencia para el desarrollo de 
estas tres líneas, parece conveniente una breve exposición -ausente de aportaciones personales - sobre el proceso de formación de las actuales provincias tal y como es conocido.

\section{El estado de la cuestión}

El primer intento oficial de reorganización del territorio español en nuestra historia contemporánea se encuentra en el decreto de José Napoleón I, fechado en Sevilla el 17 de abril de 1810 (1). Se trata de una división en 38 prefecturas (39 en 1811 con la incorporación de Segovia) que reciben el nombre de sus respectivas capitales. Se apartaba en esto del proyecto preliminar atribuido a Juan Antonio Llorente, donde se contemplaba la creación de 38 departamentos con denominación geográfica, principalmente fluvial (2). Fuera éste o más bien Francisco Amorós su principal responsable (3), el juicio de A. Melón parece seguir en pie: «La división josefina es del mismo carácter y aún más revolucionaria, en el sentido de ladear legalmente todo recuerdo de la tradición histórica, que la división departamental impuesta a Francia por la Asamblea Nacional constituyente del año 1791» (4). En efecto, las prefecturas, con sus correspondientes divisiones (ciento diez subprefecturas capitales novedosas, una extensión más o menos armónica y limitadas por trazos que aprovechaban los accidentes del terreno, recordaban poco la organización territorial del Antiguo Régimen. J. Mercader Riba ha demostrado - contra el supuesto habitual- la vigencia administrativa de esta división durante la guerra (5), pero es obvio que cayó en desuso con la retirada progresiva del ejército francés.

(1) Cfr. Prontuario de las leyes y decretos del Rey nuestro Señor Don José Napoleón l del año 1810 (Madrid, Imprenta Real, 1810) 56 y ss., «decreto por el que se establece la división del gobierno civil de los pueblos del Reyno en Prefecturas, y demarcación de sus límites» (Sevilla, 17 IV-10).

(2) Cfr. A. MELON, «EI mapa prefectural de España (1810)m, en Estudios geograficos, XIII/46 (1952), 11; vid. también «De la división de Floridablanca a la de 1833n, en loc. cit., XIX/71 (1958), 173-220; «La división provincial de 1833 erróneamente calificada», en BRAH, CLII (1963), 95109. Una sintesis de sus aportaciones sobre la división josefina, en J. MERCADER RiBA, José Bonaparte, Rey de España (1808-1813). II. Estructura del Estado español bonapartista (Madrid, CSIC, 1983), 203-234; en general, los historiadores españoles han tendido a desentenderse de esta división, por considerarla desligada del proceso de formación de las provincias.

(3) Vid. la comunicación de G. Dufour, «Le centralisme des "Afrancesados"», en Nationalisme et litterature en Espagne et en Amerique Latine au XIXe siècle (Colloque international organisé en fevrier 1980 par le centre d'etudes iberiques et ibero-americaines du XIXe siècle. Etudes reunies par Claude Dumás) (Lille III, 1982), 11-24; da a conocer los trabajos afrancesados preliminares, esto es, el proyecto contenido en el Reglamento para la Iglesia española (mayo de 1808) de Llorente, y la División nueva de la España en departamentos. Trabajado en Burgos por orden del rey el día 16 de noviembre de 1808 por don Francisco Amorós (este último, publicado en pp. 18-22).

(4) A. MELON, «La división provincial (...) m, art. cit., 99

(5) J. Mercader, o. c., 233-234; aen cambio, lo que ya no parece tan seguro es que se siguieran fielmente los límites trazados por las explicaciones anejas al decreto de abril de 1810 . 
Entretanto, el gobierno y las Cortes de Cádiz tampoco permanecieron ociosos sobre esta cuestión (6). La división provincial era, en efecto, una exigencia de la Soberanía Nacional y de la igualdad de régimen jurídico formuladas en la Constitución de 1812. En consecuencia, la provincia se configuraba como circunscripción electoral, marco fiscal para una contribución territorial igualitaria y como unidad de organización de la milicia nacional. Objetivos principalmente políticos por tanto - concluye Calero- y sólo administrativos de manera complementaria (7).

La preocupación de las Cortes cuajó en el encargo comunicado el 26 de junio de 1813 a Felipe Bauzá, marino y geógrafo distinguido que entonces se encontraba al frente del Depósito Geográfico. Poco menos de tres meses después, el 21 de septiembre, entregó al gobierno su proyecto de división en 44 provincias. Este resultado de la combinación de cuatro bases distintas - población, riqueza, extensión y la necesidad de contar con las «preocupaciones», es decir, los prejuicios y costumbres de los habitantes - era sin duda algo confuso. Hasta cierto punto, Bauzá o el corrector posterior, Miguel de Lastarría (8) consiguió salvar los límites históricos de algunas provincias, pero sin duda predominó el criterio de población que aplicó rigurosamente en las cuatro provincias gallegas, cada una con 316.386 almas (9). Todo ello a costa de una compleja clasificación de las provincias en tres categorías; las de primera - dotadas de mayor riqueza y extensión - se subdividian dando origen a provincias subalternas o de tercera clase, que denominó alternativamente partidos y gobernaciones. El expediente pasó al Consejo de Estado, que redujo las 44 provincias a 39 y simplificó algo el esquema de clasificación. Allí se encontraba todavía al parecer en mayo de 1814,

(6) De todo este proceso, los proyectos liberales de 1813 y 1821 (donde se ha visto una relación directa con el decreto de 30 de noviembre de 1833) son sin duda los mejor estudiados. Entre los trabajos recientes, vid. especialmente: A. GUATIA, aLa división provincial y sus modificaciones», en Actas del III Symposium de historia de la Administración (Madrid, IEA, 1974). 309-352, estudio principalmente comparativo; G. MARTINEZ DIEZ, "Génesis histórica de las provincias españolas», en AHDE, LI (1981), 523-593; Eduardo Garrigos PIco, «Organización territorial a fines del Antiguo Régimen», en La economía española al final del Antiguo Régimen. IV. Instituciones (Madrid, Alianza Editorial/Banco de España, 1982), 1-102; utiliza ya la documentación del ACE que empleó Concepción DE CASTRo en su apretada sintesis, contenida en La revolución liberal y los municipios españoles (Madrid, Alianza Editorial, 1979), 58-61; sobre las mismas fuentes, vid. también A. CALERO AMOR, «Liberalismo y división provincialn, en Revista de historia contemporánea, núm. 3 (1984), 5-31; analiza los criterios operativos de la división y la relaciona con el establecimiento del Régimen constitucional.

(7) Cfr. A. Calero, art. cit. 14; vid. también I. OlabarRi Gortazar, "Un conflicto entre nacionalismos: la "cuestión regional" en España, 1808-1936», en La España de las Autonomias. Obra coordinada por Fernando Fernández Rodriguez (Madrid, IEAL, 1985), especialmente 83-85; sobre la relación entre el principio revolucionario de igualdad y el auge de la administración (en función de la exposición de Tocqueville), E. Garcia EnTERRiA, Revolución francesa y Administración contemporánea (Madrid, Taurus, 1981). 43-49.

(8) Cfr. E. Garrigos, art. cit., 61-63.

(9) Cfr. A. Calero, art. cit., 20. 
cuando el cambio de Régimen impidió que las Cortes lo discutie$\operatorname{ran}(10)$.

Con el restablecimiento del sistema constitucional seis años después, este proceso continuó. Sería farragoso y no muy útil aquí, una descripción minuciosa de los trabajos y las sucesivas modificaciones que introdujeron las comisiones y el pleno de las Cortes hasta la promulgación del decreto de 27 de enero de 1822, donde se establecía con carácter provisional la división en 52 provincias, considerada generalmente como el precedente inmediato de la del año 33. Sí importa en cambio recalcar - se ha advertido de manera unánime- el sentido de continuidad respecto a los trabajos de 1813, ya que el proyecto básico fue nuevamente encargado a Felipe Bouzá, en colaboración -esta vez- con José Agustín de Larramendi.

Se mantenía en la división de 1822 la prioridad de objetivos políticos sobre los administrativos, a cuyo fin se estimó preferible la creación de un número mayor de provincias - pero más pequeñas, y por tanto más manejables- al complicado esquema de 1813 . Técnicamente, esta conversión debió simplificarse bastante cuando la comisión de Cortes abandonó la base de «riqueza» (o sea, la pretensión de uniformidad en los recursos económicos de cada provincia) ciñéndose, como al parecer, habían hecho ya los proyectistas afrancesados, a los criterios de población, extensión y límites naturales.

El primero de estos criterios, contar con un número proporcionado de habitantes en cada provincia, era lo idóneo desde el punto de vista del gobierno político y la representación electoral. Pero lógicamente, la población no se distribuía de manera homogénea en el territorio, y esto tenía serios inconvenientes. Como expresó el diputado aragonés Miguel Cortés, cuya cita recoge Calero (11) «la acción del gobierno "está siempre en razón inversa del cuadrado de las distancias"». La extensión territorial, pues, debía ser tenida en cuenta al trazar la división. Claro que los accidentes del terreno - sierras, valles, ríos, etc.- obstaculizaban, o facilitaban en su caso las comunicaciones, colaborando en la formación de auténticas áreas de relación. En resumen, la topografía venía a corregir, fijando los límites, el criterio de extensión.

(10) Concepción de Castro, Gonzalo Martínez Díez y Antonio Calero coinciden en la afirmación de que el expediente fue retenido por el Consejo de Estado: ano debe darse un paso tan transcendental -dice- sin una previa elaboración de estadísticas y otros estudios de carácter político, económico, judicial y militar» (Consulta del Consejo -6-IV-14-, en C. DE CAstro, o. c., 58 n.). En este punto, como en otros relativos a los trámites y descripción de este proyecto, Garrigós se separa de la versión más habitual al explicar que el proyecto, modificado por M. Lastarría, fue al fin remitido a la comisión de Cortes. No justifica esa discrepancia (art. cit., 64).

(11) A. Calero, art. cit., 21; sigo su exposición («los criterios de formación de provincias», pp. 17-21) de modo muy ceñido en estas líneas. 
Es preciso referirse también a «las preocupaciones del provincialismo», algo que estuvo en la mente de todos y pesó durante la discusión de las Cortes. En consecuencia, se procuró en lo posible no mezclar los diferentes territorios históricos y se conservaron casi siempre las antiguas divisorias de los municipios cuando éstas entraban en conflicto con los nuevos límites provinciales. Puede parecer por tanto algo forzada la afirmación de A. Guatia, quien se refiere al «carácter conscientemente ahistórico» de la división de 1822 (12), pero es cierto que sobre el respeto a las antiguas tradiciones y particularismos, predominó en general la voluntad de potenciar un espíritu nacional. Luego volveremos sobre ello.

Para terminar con esta síntesis sobre el proceso de formación provincial tal y como lo conocemos, es ineludible la referencia a la división en 49 provincias por Real Decreto de 30 de noviembre de 1833, que básicamente continúa hasta hoy en vigor. Debe advertirse que el expediente que originó dicha división nunca ha sido localizado, ni por tanto utilizado por los investigadores. Ahora bien, su similitud con la de 1822 ha conducido a cuantos se han ocupado del tema, desde Guatia a la actualidad (13), a establecer una estrecha relación de dependencia entre ambas: la división de 1833 - se ha llegado a decir - no sería sino la del Trienio, con algunos cambios de relativo alcance, ciertamente no de fácil explicación. En efecto, mes y pico de ministerio (Javier de Burgos fue nombrado el 21 de octubre de 1833) no daba para una obra de esas dimensiones, que requería buenos mapas, conocimientos especiales, un laborioso trabajo de gabinete, etc. En fin, según esta hipótesis el mismo decreto de 30 de noviembre reconocería, siquiera de una forma velada, la deuda contraída con la división de 1822 e incluso con los trabajos de rectificación presuntamente realizados durante el Trienio: «Así lo habéis verificado después de haber reconocido los prolijos trabajos hechos antes de ahora por varias comisiones y personas sobre tan importante materia» (14). EI ministro Burgos, en consecuencia, no habría hecho otra cosa prácticamente que firmar el decreto y ocultar sus fuentes, ya por prudencia política, ya por afán de gloria personal.

Esa influencia es clara. Como hace notar G. Martínez Díez, la división de 1833 sigue a la de 1822 en el número de provincias (49 y 52 respectivamente) y elección de capitales «con las únicas modificaciones de suprimir las provincias de Játiva, Calatayud y EI Bierzo, y cambiar la capitalidad de Vigo a Pontevedra y de Chinchilla

(12) A. GUAITA, art. cit., 325.

(13) Ibidem, 328: «Básicamente, esta división de 1833 es la misma de 1822: en unos puntos la confirma o sigue muy de cerca; en otros la varía o rectifica, por lo común y en mi opinión. mejorándolax.

(14) Col. Dec., XVIII, 289, aR.D. mandando, hacer la División Territorial de Provincias del modo que se contiene en seguida» (30-XI-33). 
a Albacete» (15). Por otra parte, según datos de Calero ambas divisiones coinciden, provincia a provincia, en una proporción del territorio que no baja del 75 por 100 (16).

$Y$ sin embargo, existen a la vez diferencias notorias que merecen explicarse, si es que se desea acceder desde esta perspectiva a la comprensión de procesos históricos con mayor envergadura. Tales divergencias consisten en primer lugar, en el «espíritu», si así puede hablarse, de la división de 1833. Burgos la planteó con fines estrictamente administrativos - como marco de actuación para los subdelegados de Fomento- y no políticos, en la acepción liberal democrática. Segundo: se trata de una división condicionada en buena medida por el criterio histórico. Este se manifiesta en bastantes aspectos, entre los que destacan la elección parcial de la antigua toponimia (Vizcaya, Navarra, etc.) y la conservación de límites tradicionales en gran número de casos. De hecho, se ha afirmado, el plan consistió más en un fraccionamiento interno de los reinos preexistentes que en una auténtica remodelación del territorio peninsular (17).

Desde mi punto de vista, el intento de explicar estas divergencias pasa por un análisis del pensamiento del ministro de Fomento que planteó la división, Javier de Burgos, y por una reconstrucción del proceso durante un período poco tenido en cuenta hasta ahora: la década de 1823-1833. Es la pauta que me propongo seguir a continuación.

\section{Los «arreglos» durante la década final del reinado de Fernando VII}

La historiografía sobre el tema ha sido unánime en afirmar que no hubo nuevos intentos de reforma durante el período 1823-1832, lo que desde luego, era coherente con la ausencia de realizaciones positivas que durante años, se ha achacado a la "Ominosa Década». Sólo E. Garrigós Picó sospechó algo de la verdad en este punto, al

(15) G. MARTINEZ Diez, art. cit., 587

116) A. CALERO, art. cit., 10: «Una comparación detallada, provincia por provincia, de ambas divisiones demuestra que el territorio coincide, en una y otra, en una proporción que puede estimarse, como mínimo, en torno al 75 por 100. Y si se exceptúan las provincias afectadas por la supresión del Bierzo, Calatayud y Játiva, la coincidencia territorial puede estimarse en torno a un 85 ó 90 por 100»; en el mismo sentido, vid. Garrigos, art. cit., 74: «Salvo los cambios de territorios ocasionados por las provincias que desaparecen, las extensiones territoriales de las provincias que hemos contrastado, salvo ligeros retoques, son prácticamente las mismas».

(17) Los aspectos mencionados con más frecuencia son: el empleo en parte, de la antigua toponimia; clasificación de las provincias por regiones; conservación del perímetro exterior de los antiguos reinos (especialmente evidente en Galicia, Navarra, Aragón y Cataluña); respeto a los límites municipales, también cuando entraban en conflicto con la nueva raya provincial (se contemplaba también en la división de 1822); permanencia de algunos enclaves (Orduña, Treviño, Petilla, etc.); preferencia por las antiguas capitales (vid. especialmente A. GuAITA, art. cit., 328, y E. GARRIGOS, art. cit., 73-74). 
haber localizado una información donde se insinuaba la remodelación de los partidos judiciales extremeños hacia 1829 (18). Sin embargo, el carácter fragmentario de los datos, junto al prejuicio mencionado, le impidió extraer conclusiones al respecto.

En realidad, la imagen de esos años, en lo que se refiere al reformismo económico y técnico, va mejorando en la medida en que progresa la investigación histórica: hoy en día parece incuestionable que sí se realizó un proyecto de división territorial — promovido desde instancias oficiales - y que éste fue el sancionado con algunos retoques en 1833. Por supuesto, el expediente fundamental nunca ha sido localizado (19), pero algunas fuentes colaterales son suficientes para dar una idea de los hitos principales del proceso, ya que no para una reconstrucción con detalle.

Contra lo que podría suponerse, el proyecto no se encuadra en el contexto ilustrado y reformista que caracterizó la gestión del ministro de Hacienda, Luis López Ballesteros. Este, como es sabido, había impulsado iniciativas como el sistema de presupuestos, las exposiciones nacionales de la industria o el proceso institucional que culminaría en la creación del ministerio de Fomento. Fue también, desde luego, el protector de un grupo significativo de antiguos afrancesados, a quienes empleó a menudo como asesores y técnicos en diferentes operaciones del ministerio (20).

Por el contrario, el nuevo proyecto de división territorial tuvo su origen en un grupo rival - dependiente del ministerio de Gracia y Justicia- y se concibió casi con seguridad, como una de las piezas principales de la reforma de la administración judicial que apadrinaba Francisco Tadeo Calomarde. En efecto, en el Consejo de ministros del 3 de noviembre de 1825 presentó a sus colegas una memoria sobre

(18) Cfr. E. Garrigos, art. cit., 70, citando a M. Muñoz de San Pedro, Extremadura en 1829 (Diputación provincial de Cáceres, Cáceres, 1966), sin página: «Extremadura, según los datos que le proporciona el Archivo de la Diputación de Cáceres, presenta una organización territorial judicial de diecisiete partidos frente a los nueve partidos que integraban la división judicial de la provincia en 1790 que nos indica que se ha producido una redistribución del territorio en el plano judicials.

(19) Mi búsqueda en los archivos más probables - AHN, AGP, ACE, Ministerios de Justicia, Interior, Relaciones con las Cortes, Consejo de Estado- no tuvo éxito. Cabe la posibilidad de que el expediente ardiera en 1939, junto a otros fondos de Fomento depositados en Alcalá de Henares.

(20) La falta de relación entre López Ballesteros y los hombres de la división territorial queda bien clara en los Diarios de Arias Teijeiro, cuando éste se refiere a los comisionados: «Le pedía Cabirtos [a López Ballesteros] que trabajase porque la Puebla fuese cabeza de partido; contestó que en eso entiende Lamas Pardo, a quien nada pediría (no es extraño)»; o bien: «Larramendi charla de caminos: hablé del de Vigo a Orense y convino. Quiere dar un mapa a Ballesteros para que adopte la división de provincias, base de todo, dice» (J. ARIAS, "Diarios de 30-VI-29 y 11 -IV30", en Seminario de Historia Moderna, Documentos del reinado de Fernando VII. III. Arias Teijeiro. Diarios (1828-1831). Introducción y notas por Ana María Berazaluce (Pamplona, Universidad de Navarra y CSIC, 1968, I, 173, y II, 172); en lo sucesivo cito esta fuente de manera abreviada. 
la reforma de los escribanos, un expediente sobre la conveniencia de disminuir el número de días feriados en que vacaban los tribunales y a continuación,

«una exposición que el Sr. ministro de Gracia y Justicia ha elevado a S.M. haciendo presente lo útil que sería el arreglo de los Tribunales y juzgados inferiores por los incalculables prejuicios que se originan a los particulares de tener que ir a grandes distancias para que se les administre justicia y por la imposibilidad en que se ven los magistrados de ejercer su vigilancia en puntos muy distantes de aquel en que residen. En apoyo de esto presentó un plan del que aparecía que en la provincia de Córdoba corresponde a cada corregidor siete mil almas y nueve leguas cuadradas de territorio, y hay otras en que corresponden a cada uno de estos funcionarios públicos cuarenta, noventa y cien mil almas, y así mismo cuarenta, cincuenta y aún cien leguas cuadradas. Para remediar tamaños males propone el Sr. ministro que se haga una nueva demarcación de todos los juzgados, y que para obrar con el debido conocimiento, se ocupe su secretaría en adquirir las noticias más exactas posibles de la población de cada provincia, etc. Y el Consejo acordó proponer a S.M. que se instruya este expediente; exponiéndole al propio tiempo que siendo este asunto del mayor interés, como así mismo los que se han tratado en esta sesión, y habiendo pendientes otros negocios arduos, convendría se reuniese el Consejo de Estado, para que el Ministerio pudiese contar con las luces y autoridad de un cuerpo tan respetable» (21).

Por lo que se sabe, el hombre que inspiró a su ministro y se ocupó en buena parte de estos arreglos, se llamaba José Lamas Pardo, era oficial en Gracia y Justicia y sustentaba - ya entonces- opiniones realistas a toda prueba. Gallego (nacido en San Miguel de Saldange, 1790), había sido rector de la universidad de Santiago, donde se labró según parece, un buen prestigio durante su mandato. Fue sustituido en septiembre de 1818 (22), tardando pocos meses en ingresar como oficial octavo en la Secretaría de Gracia y Justicia. Al quedar cesante en el Trienio, Lamas fue diputado suplente por Lugo durante la

(21) Archivo del Ministerio de Relaciones con las Cortes, Actas del Consejo de Ministros (3. XI-25), 128-129; Calomarde presentó también el proyecto de Reglamento sobre Escuelas de latinidad y Colegios de Humanidades, con lo que acaparó prácticamente esa sesión.

(22) Cfr. AHN, Cons., 50.903, Lozano de Torres al presidente del Consejo (14-IX-18); vid. también aquí la Memoria sobre los exámenes públicos en las cátedras de universidades, que por primera vez celebró la Real Universidad de Santiago en los dias 25, 26, 27 y 28 de junio del año de 1817 conforme al reglamento comunicado por la última Visita regia de año de 1816 (Imprenta de D. Juan María de Pazos, 1817). 
legislatura de 1821 (23) y - según Ana Berazaluce - secretario de la jefatura política en esa provincia (24). Pero no fue el suyo un liberalismo muy perseverante: hacia mayo de 1825, al iniciarse el expediente de su ingreso en la orden de Carlos III (25), se encontraba de nuevo en Gracia y Justicia - ahora como oficial segundo- de donde pasó a cubrir una vacante en el Consejo de Ordenes tres años después. Arias Teijeiro, colaborador y amigo de Lamas, criticaría a Calomarde con este motivo: «¿Por qué priva a la Secretaría del mejor de sus oficiales, del más instruido, del más realista, del más laborioso, del que ha promovido los arreglos con que él está engañando al Rey al paso que los entorpece, en fin, del único hombre de los ministerios?» (26).

Como el Consejo de Estado estaba desarticulado en 1825, hay cierta lógica en el hecho de que Calomarde desarrollase sus reformas por vía exclusivamente ministerial. En este sentido, la prensa de 1833 menciona sin equívoco posible la creación, por Real Orden de 16 de diciembre de 1825, de una «comisión encargada de proponer al gobierno las reformas, división y arreglos convenientes, tanto en el orden y administración de la justicia, como en la planta y distrito de los tribunales y juzgados». Su objeto específico sería según el Boletín del Comercio (27), proponer «las reglas más adecuadas para evitar los males que causaba la desigual y monstruosa división del territorio español». Confirmando esa información, el Eco, sucesor del Boletín, revelará siquiera en parte, quienes fueron los componentes de la junta de 1825: Agustín de Larramendi, Martín Fernández Navarrete y "otros sujetos que presentaron su proyecto de demarcación de límites de las provincias» (28).

(23) Cfr. AHN, Hacienda, 1.249/105 (clasificación cesantes); había servido cinco meses en la Secretaría hasta su cese, en 5-V-20.

(24) A. Berazaluce, Introducción a Arias Teijeiro (...), I, 59 n, con más datos biográficos y diferentes fuentes; afirma que Lamas siguió a don Carlos durante la guerra, lo que no es muy extraño, de acuerdo con la información proporcionada por las Actas del Consejo de Ministros: $\alpha \mathrm{EI}$ propio Superintendente [José Manuel Arjona] manifestó también que consideraba perjudicial la permanencia en esta Corte del Consejero de Ordenes don José de Lamas Pardo por sus opiniones carlistas que hacia comunicativas a otros, imbuyéndoles sus mismas extraviadas ideas; $y$ habiendo meditado el Consejo sobre el particular, acordó que convendría hacerle salir desde luego para el Puerto de Santa Maria, haciéndolo entender que se le comunicarían allí las órdenes que S.M. tenga a bien darle» (Actas C.M., 11.VIII-33, p. 261).

(25) Cfr. AHN, Estado (Orden de Carlos III), expte. 1.922.

(26) Arias TEIJEIRo, Diarios (19-II-28), I, 57

(27) aDivisión territorial», en Boletín de Comercio, 84 (2-1X-33); el artículo responde -o mejor, complementa- el de la Revista Española, 83 (6-VIII-33), 759, sobre «Estadistica»; éste defendia la necesidad de la división del territorio, como operación previa al establecimiento de dependencias y autoridades subalternas de Fomento, tesis lanzada a su vez por el Boletín, 75 (2-VIII-33), «Sobre el Ministerio de Fomento».

(28) aDivisión judicials, en Eco del Comercio, 16 (16-V-34); la identidad entre los redactores del Boletín y los del Eco no ofrece dudas. Tanto por su especialización como por su línea política habitual -sumamente crítica a los ministros Cea, Burgos y, en general, al equipo afrancesado- 
Esos dos nombres son de por sí, suficientemente significativos. Fernández Navarrete, marino y erudito bien conocido, era amigo personal de Felipe Bauzá, a quien sucedió en el Depósito Hidrográfico cuando éste hubo de exilarse del país en 1823 (29). En cuanto a Larramendi, entonces ingeniero cesante de caminos y canales (30), interesa recordar que si había sido encumbrado durante el Trienio Constitucional, era precisamente por su colaboración con Bauzá en el proyecto aprobado por las Cortes en 1822. Parece razonable concluir, por tanto, que las personas de que echó mano Calomarde para realizar la división de las provincias - parte importante de la reforma judicial- poseían la preparación adecuada, y contaban con los antecedentes necesarios para desempeñar esa misión. Desgraciadamente, no es conocida por ahora fuente algun que pudiera informar sobre el desarrollo de los trabajos hata la intervención de Lamas Pardo, ya en fecha posterior. Pero como por otra parte, su propia labor no era ajena en absoluto a la de la comisión, vale la pena seguirla por ahora en calidad de hilo conductor.

En enero de 1828 Lamas llevaba ya tiempo ocupándose - con la colaboración de su paisano José Arias Teijeiro y de algún otro auxiliar - de la división de corregimientos y partidos judiciales de la

Fermín Caballero y Morgáez podría haber sido el autor de éste, y otros artículos semejantes. Ya en 1834, su hostilidad contra el gabinete llustrado le llevará a subrayar la dependencia de la división territorial aprobada el año anterior, respecto al proyecto de la comisión de 1825.

(29) Vid. la semblanza bio-bibliográfica de Martín Fernandez NAvarRete en apéndice a Biblioteca marítima española. Obra póstuma, Il (Madrid, Calero, 1951), 436-470; también, Obras, I (edición y estudio preliminar de Carlos Seco Serrano), BAE, 75 (Madrid, 1954); H. JURETSCHKE (Los afrancesados en la Guerra de la Independencia. Madrid, Rialp, 1962) pone de relieve - para los años de la guerra- el carácter ponderado del personaje, a quien no costó gran trabajo obtener su purificación cuando los franceses abandonaron Madrid. Tampoco fue molestado en 1823. Ninguna de estas obras se hace eco de su colaboración en el proyecto de división encargado a la junta de 1825, dato que únicamente menciona su bien surtida hoja de servicios: «Por otra Real Ordén de 16 de diciembre de 1825 fue nombrado vocal de la junta creada para hacer una división territorial concerniente al arreglo de los tribunales de provincia y juzgados inferiores, con trascendencia también a la división militar, económica y política» (AHN, Hacienda, 2.800/347, Cesantes y jubilados).

(30) Cfr. AHN, Hacienda, $3.370 / 433$ (clases pasivas, 1841); nacido el 1 de abril de 1769 en Mont-Real de Deva, Valle de Mendaro(sic.), Guipúzcoa. Fue profesor de «ingenieros cosmógrafos del Estado» desde 1796, y Comisario de caminos y canales en 1799. Conservó el empleo y vivió en Madrid durante la dominación francesa; purificado y reintegrado a su ocupación y sueldo en 1815: «no está en la categoría de compradores de bienes nacionales, pues aunque intentó su compra, no llegó a verificarla». Director general de caminos y canales en el Trieno, fue cesado en 1823. Tres años después - 5-XI-26- se le reintegraban los honores de Intendente de provincial y el sueldo que disfrutaba en 1829 «atendiendo a los distinguidos méritos y servicios de V.S.». Ascendió a la Dirección general de Correos el 21-XII-29, lo que dio lugar a un rumor que recoge Arias Teijeiro: «que Salmón ya cayó porque nombró Director a un pícaro como Larramendi, de lo que Melgar se quejó al Rey (bueno, bueno, Salmón está sostenido por Calomarde, y acaso éste es quien nombro a Larramendi...) (ARIAS, Diarios, 13-I-39, II, 20); vid. ibidem (20-III-30), II, 139, sobre su dependencia a Calomarde: «El ministro dijo a Larramendi que quería su trabajo y todo corriente, para el día de San Fernando; le contestó que él no podía, y que lo encargase a otro si queria». Al desdoblarse la Dirección el 23-X-33. Santiago Usoz quedó en Correos, pasando Larramendi a Caminos. 
península, si bien, algunas expresiones del propio Arias dan a entender que no contaba con el respaldo total de su ministro: «N. sigue atacando con sus notas, que pone literales en las listas, de modo que S.E. tiene que leerlas al Rey. No se por qué fatalidad se ha suspendido el deseado arreglo de juzgados - dice en una- sólo lo ocurrido en esto bastaría a desacreditar a tal ministro» (31). La promoción de Lamas al Consejo de Ordenes el 20 de febrero de ese año (interpretada por Arias como un modo de privarle de su influyente posición en el ministerio) se tradujo en un alejamiento temporal de los «arreglos». Sin embargo, Calomarde debió cambiar de opinión, puesto que a mediados de agosto ofreció a Lamas la presidencia de una junta con ese objeto. Este, que no parecía tener motivos para apreciar a su ministro, dio largas de momento (32), pero terminó por hacerse cargo del asunto algunos meses después, cuando la fobia común a López Ballesteros propició un açercamiento entre ellos. En el curso de una nueva entrevista el 15 de diciembre, Lamas se quejó de lo que parecía una personalidad del ministro de Hacienda, a lo que Calomarde respondió: «No eran amigos de $V$, no. Añadió que Ballesterios era malísimo, protector decidido de todos los afrancesados en todos los ministerios; que a él jamás le perdonaría haberle echado abajo su junta, etc.» (33). Pocos días más tarde, refiere Arias, se oficiaba desde el Pardo a Lamas encargándole de los «arreglos» (34).

Es evidente que el ritmo de los trabajos estuvo a partir de entonces muy condicionado por la metodología seguida: de acuerdo con lo expuesto por Calomarde en el Consejo de ministros del 3 de

(31) ARIAS, o. c. (30-1-28), I, 42; los Diarios - los que se conservan $y$ han sido editados por Ana María Berazaluce-comienzan en enero de 1828 y terminan a finales de mayo de 1831 , cuando su autor marchó a Galicia para tomar posesión de una toga que obtuvo para él Lamas Pardo, como premio a sus servicios. Lamentablemente, las anotaciones son con frecuencia muy oscuras y existen lagunas de consideración: enero a mayo y octubre a diciembre de 1829, y agosto de 1830 a marzo de 1831

(32) Ibidem (18-VIII-28), I, 117: «El señor Lamas fue a ver al señor Calomarde. Le recibió muy bien: le dijo que contase con su afecto; que no le quería en Ordenes; que iba a encargarle de los arreglos de marras (ya han conocido la necesidad) y a nombrarle presidente de una junta para ello, etc. Lamas dijo que su ambición estaba satisfecha; que él no pedia encargarse de nada (además de que jamás opinó por juntas), pues su salud quebrantada no le permitia, ni la necesidad de instruirse en la legislación y en la práctica de los tribunales, cosa que no pudo hacer en la Secretaríax.

(33) Ibidem (15-XII-28), 1, 147; se refiere a la Junta General de Fomento de Reino, proyecto que canalizaba los afanes reformistas del equipo de López Ballesteros. Los decretos de erección. reglamento y nombramientos llegaron a imprimirse en agosto de 1828 , pero en el último momento el rey fue disuadido de esta iniciativa. Vid. P. MoLAS, «De la Junta de Comercio al ministerio de Fomento», en IV Simposio de Historia de la Administración (Madrid, IEA, 1984). 529-556.

(34) ArIAS, o. c. (17-31-XII-28), I, 149: «Yo le aconsejé que no se encargase de una cosa que al fin, no había de tener más resultados que disgustos y compromisos para él; y que además le degrada si ha de poner órdenes, etc., y degrada a la Secretaria que no es capaz de llevar a cabo esta obrax. 
noviembre de 1825, era necesaria la obtención de determinadas noticias sobre la población de cada provincia; ahora bien, por el motivo que fuera, las chancillerías, audiencias y ayuntamientos consultados por Reales órdenes e instrucciones de 22 y 31 de marzo de 1829, remitieron datos que iban mucho más allá del objeto inicial. Según el Eco, la falta de uniformidad en esta información habría perjudicado seriamente la obra de Lamas (35), y algo de esto refleja también el Diario de Arias, buena fuente - a pesar de las importantes lagunas en los cuadernos de 1829 - para obtener una visión de conjunto sobre el desarrollo de los trabajos:

«EI Sr. Lamas fue a despedirse del ministro: grandes obsequios. Calomarde dice que no hay que temer a la revolución; pero a poco, supone lo contrario. Repite que el Rey siempre está preguntando por los arreglos, que él tiene el mayor interés por ellos, etc.

Van viniendo menos mal los arreglos. Sólo Galicia empeñada en echarlo todo a perder: la división de corregimientos es la del tiempo del diablo; los comisionados, un relojero, Conde, amigo de Sánchez Boado y otros tales: véase lo que Padre escribe. Mil mentiras esparcidas aquí mismo en descrédito de las cosas, como que se ponen en Madrid seis jueces de primera instancia, etc. Ya se ve: cuando se organiza

(35) Eco del Comercio, $16(16-\mathrm{V}-34)$ : $\alpha$ Es indudable que a la par que se reunieron $y$ rectificaron muchas noticias, se incurrió en otros inconvenientes, inevitables en el sistema de nuestros informes de oficio, comunes en cuerpos tan ajenos de este género de negocios, y propios además de la época en que se intentaba hacer lo que requería otras circunstancias. Los expedientes formados en los Tribunales superiores carecían en primer lugar de unidad de plan; se confiaron a las secretarías de los Acuerdos que los desempeñaron mediante informes de los Alcaldes mayores; influyó mucho en su instrucción la rivalidad de unos pueblos con otros, el espíritu de partido y las consideraciones personales; en una palabra, se multiplicaron trabajos inconexos, que la laboriosidad del comisionado no acertó a depurar, y que era imposible produjesen resultados seguros, careciendo de la base esencial de un buen mapa topográfico de Españax; respecto a los mapas, parece que se utilizaron el de un tal Bustamante - afrancesadoy el de Galicia, tódavía no acabado, de Domingo Fontán. Este último se tuvo en cuenta también para «el general de España que están haciendo» (ARIAS, o. C., II, 194 y 259). Domingo Fontán Rodríguez (Caldas del Rey, 1788-Baños de Cuntis, 1866) era catedrático de matemáticas en Santiago, y desempeñó el cargo de secretario de la diputación de la Coruña en el Trienio. Obtuvo su purificación en agosto de 1826, por mediación de Juan Miguel Grijalva, Jacobo María de Parga, Lamas Pardo y Sebastián Miñano; éste le puso en relación con López Ballesteros, su mecenas para lo sucesivo. Con referencia a su «Carta geomética de Galicia él mismo afirmó: «Esta obra no sólo fue conocida y recomendada al Gobierno su publicación, por la noticia que de ella y de su autor daba Miñano, sino que también era conocida y de ella se servía en trabajos muy útiles de la división judicial y municipal de Galicia el Sr. O. José Lamas Pardo, oficial 2 mayor de Gracia y Justicia, compañero de Fontán y amigo suyo desde la niñez» («Datos biográficos de $D$. Domingo Fontán Rodríguez», en Consejo Superior de Investigaciones Científicas. Instituto Padre Sarmiento, D. Domingo Fontán y su mapa de Galicia en el primer centenario de su publicación. Cuadernos de Estudios Gallegos, anejo I, Santiago de Compostela, 1946, 67). 
el desarreglo general, debe ser sospechoso, al que no está en datos, tal arreglo» (36).

Las dificultades, obviamente, no eran de índole puramente técnica: hubo de afrontar la presión de los poderosos en favor de tal o cual pueblo como cabeza de partido (37), las veleidades de Calomarde («trata, creo, de hacer una picardía al señor Lamas»), o una falta de cooperación motivada según Arias, tanto por una disculpable desconfianza ante las operaciones del gobierno («todos los pueblos están alarmados con nuestros arreglos. Se conoce la necesidad manifesta, pero como salen del Gobierno, todos temen») como por la evidente reminiscencia de la época constitucional. Se entiende bien que esta última circunstancia sacara de sus casillas a gente tan caracterizada - desde un punto de vista ideológico- como era el grupo de Arias: «El Señor Lamas Pardo contestaba con oportunidad al Señor Vélez, que con socarronería le decía que escribian que el arreglo era el mismo que el de los constitucionales (falta de paciencia para oír tales sandeces): Yo estoy satisfecho de lo que hago mientras no lo veo alabado en la Gaceta de Bayona, Correo Mercantil y otros papeluchos que VV. pagan sin deber hacerlo. Sin duda nada más cierto. Jiménez dice que cuantos verdaderos realistas van por la Secretaría, preguntan que cuando se realizarán unos arreglos por los que todos los hombres de bien suspiran» (38).

A mayor abundamiento, la ley de Escribanos parece haber cobrado preferencia desde el mes de septiembre sobre el resto de los «arreglos» en los que intervenía el consejero de Ordenes. Consiguió entregar este expediente integro en enero de 1830 (39), pero el Consejo, siguiendo el dictamen fiscal («los fiscales estrivaban principalmente en decir que no está hecho el arreglo de juzgados y ayuntamientos, y que no es posible hacer indemnización a los dueños, además de impugnar los estudios, etc.») (40) terminó por reprobarlo a finales de abril. Este hecho contrarió a Calomarde, pero retuvo el expediente para su adopción posterior, al tiempo que las restantes reformas proyectadas (41).

(36) ARIAS, O. c. (3-VIII-29), I, 203; para la división de corregimientos en Galicia, vid. también I, 99-100; a su vez, Fontán escribió que el Acuerdo le encargó en 1826, «la actual división de su territorio en juzgados» ( $\alpha$ Datos biográficos [...], manuscrito $\alpha d x$, en loc. cit., $65 \mathrm{n}$ ).

(37) Cfr. ArIAS, o. c. (6-VIII-29), I, 205: «Guillén pide al Sr. Lamas que Gata sea capital de partido (es el confesor de don Carlos) ×. Deja constancia de no menos de ocho pretensiones de ese estilo - más de un intento de soborno- entre 1829 y 1831.

(38) Ibidem, U, 254, 211 y 163 para los anteriores entrecomillados.

(39) Cfr. Ibidem (9-1-30), II, 15: atres arrobas», comenta Arias satisfecho; en lo sucesivo, da cuenta minuciosa de los diferentes trámites y de la oposición que suscitó este proyecto, que desarrollaba el plan expuesto por Calomarde en la sesión del Consejo de ministros de 3-XI-25 (vid. Actas C.M., 1825, pp. 126-127).

(40) ARIAS, o. c. (10-III-30), II, 125.

(41) Ibidem (13-VIII-30), II, 254: «Contesta Calomarde al Sr. Lamas que se imprimirá su Exposición por cuenta de la Secretaria cuando se imprima lo demás, que será cuando salgan las 
Simultáneamente, Lamas trabajó en la división judicial — «no cesa con la tal división, despedazando lo hecho por los buenos de los tribunales»- pero quizás a causa de las dificultades surgidas (42), los progresos fueron lentos. Aquel año, el presupuesto del ministerio publicado en la Gaceta, destinaba ya el sobrante del ejercicio de 1829 -1.186 .412 rs. - más una cantidad adicional de 1.156.179 rs. «a satisfacer las obligaciones que puedan aumentarse por efecto de las mejoras que preparo, así en el nuevo arreglo de Tribunales y juzgados, como en la división de provincias y partidos». Pero Arias, burlón - «modus rapiendi», dirá- informa sobre la imposibilidad de calcular a esas alturas los caudales necesarios (43).

A pesar de todo, se había entrado ya entonces en una nueva fase de los trabajos, puesto que a primeros de febrero, Agustín de Larramendi, uno de los vocales de la junta de 1825, recibió el encargo de entrevistarse con Lamas Pardo para «rectificar los límites de las Provincias» (44). Este paso era lógico ya que para armonizar ambos arreglos territoriales, era preciso hacer coincidir los límites de las provincias con el perímetro de los partidos judiciales periféricos: ya revisando el trazado provincial, ya el de los nuevos partidos. Según el Eco del Comercio, prevaleció el segundo criterio, al utilizar Lamas como pauta la división de Larramendi y Navarrete («hubo de acomodarse a la demarcación civil acordada») (45), si bien introduciendo algunas modificaciones, de acuerdo con las consultas efectuadas a las audiencias y ayuntamientos. Por el contrario, del relato de Arias se deduce claramente que se siguieron los dos criterios, es decir, Larramendi hubo de adaptarse al proyecto de Lamas y éste a su vez, tener en cuenta las rectificaciones indicadas por el primero (46).

otras dos leyes, y que entonces saldrá la de Escribanos; y que siga en aquellas el mismo sistema que en ésta. Había añadido que lo dicho por el Consejo y sus fiscales nada valia, pero González Maldonado lo hizo quitar, porque era ofender al Consejo»

(42) Ibidem (24-VII-30), II, 269; ese aspecto, obstáculos y dificultades, es el que describe Arias con más detenimiento. Vid. por ejemplo, II, 76, sobre auna intrigan, el intento de traspasar la comisión de Lamas a la junta del Código Penal; «mas la junta, conociendo el despropósito, hizo nueva consulta y aquella orden quedó sin efecto». También II, 219: «Qué tramoyas me cuenta Prado de la división de partidos y distritos en Monforte, etc., hechos por Andrade, con Tole. Se juntaron los párrocos y particulares en casa de Cartelos; encargaron a éste el trabajo, pero murió pronto $y$ todo lo trastornaron. Los Tores agregados a Monforte y separados de Villasante $y$ Saviñao. La alcadia de Ferreira puesta para engañar a Ferreirúa, aldea miserable de Eiro, cuyo vecindario triplican - jes decir, en casa de Tole! - agregándola Acoba y Ribas de Miño que son de Sabiñao, etc. Lo del corregimiento que Quiroga, otra intriga de Lucio (...)

(43) Cfr. Gaceta de Madrid, 36 (25-III-30), y ARIAS, o. c. (27-III-30), II, 147.

(44) ARIAS, o. c. (4-II-30), II, 64: «Ayer se contestó al Sr. Lamas que se mandase a Larramendi pasase a su casa para rectificar los límites de las Provincias, para llevar a cabo una obra, cuya conclusión, decía el oficio, desea S.M. El Sr. Lamas, para evitar responsabilidades, había propuesto antes de ayer que como él no tenía antecedentes en la división de Provincias, se pasasen los papeles que ahora hay para rectificación a Larramendi o a otro vocal de la Junta que lo propuson.

(45) Eco del Comercio, $16(16-\mathrm{V}-34)$.

(46) Cfr. ARIAS, o. c. (31-III-30), II, 155: «Larramendi va a charlar con el Sr. Lamas y pedir más límites e instruirse del proyectox; también (11-V-31), III, 155: «Teijeiro viene a casa; voy con él a 
En cualquier caso, parece haberse originado entonces una relación estable entre ambos comisionados - de la que deja contancia el redactor de los Diarios - (47) hasta el punto de imbricarse en lo sucesivo el cumplimiento de los encargos respectivos: probablemente, en esta colaboración se encuentra el fundamento de una noticia publicada en la Revista Española donde se designa a los dos, Larramendi y Lamas Pardo, como autores de «la división de provincias y partidos» (48). De hecho, en la primavera de 1831 el equipo de Lamas trabajó simultáneamente y con mucho sentido de urgencia (Calomarde pretendía que todo estuviera disponible para el 30 de mayo, santo del rey) en los diferentes arreglos: Escribanos, Corregimientos y División de las provincias. No parece que el primero, una nueva versión quizás de la ley presentada en 1829, llegara a concluirse entonces. Sobre los otros dos trabajos, los comentarios de Arias son tan poco sistemáticos como de costumbre, aunque a menudo, ricos en contenido. El 5 de mayo, por ejemplo, escribió: «Traigo los papeles para poner la ley de División de Provincias. Aprueba Lamas mi idea, así como la de declarar subsistentes los Reinos y Principados actuales, etc.». O bien: «Marcamos en el mapa la división de Corregimientos de Badajoz y Cáceres que don Francisco iluminará. Pusimos también los índices de los cuadernos de estados que llevará esta división, para que vean si quieren los demás así. Con esto y con la división de provincias irá al Sitio en concluyendo nosotros ésta» (49).

Arias en persona se ocupó de la Exposición de la ley sobre división de Provincias, documento que pasó a limpio el 20 de mayo (50). Un día más tarde los comisionados firmaban el trabajo y el 22 al fin, «Lamas va al Sitio a llevar la División de Provincias: pero en mal día por las juntas famosas; como que sólo puede hablar al ministro - que se iba a ésta - un cuarto de hora escaso. Se alegró mucho con los trabajos, de que dice saca gran partido con S.M.» (51).

No queda claro en este relato si la división de partidos fue entregada también a Calomarde por aquel entonces. Según la

Lamas. Este, muy enfaenado con sus límites, rabiando contra Larramendi, porque en efecto ha hecho de cada vez mil variaciones, y cosas que parecen de intento para comprometerle».

(47) Larramendi comienza a ser mencionado en los Diarios desde febrero de 1830, como personaje de trato habitual. Casi siempre, se entiende, en relación con el tema de la división provincial y ajeno por completo al ambiente político en el que se desenvolvía Arias. Vid. II, 139, $155,172,180,183 ;$ III, 78, 155 y 176.

(48) Revista Española, 25 (29-I-33), 310: «Afortunadamente está ya concluido el importante trabajo de la división de provincias y partidos, que han desempeñado don José Lamas Pardo, del Consejo de Ordenes, y don José Agustin de Larramendi, director de Correos (...)

(49) ARIAS, o. c. (5-V-31), III, 141, y (17-V-31), III, 170.

(50) Ibidem (19 y 20-V-31), III, 174-175.

(51) Ibidem (22-V-31), III, 179; aconcluimos todo lo de la división de provincias: bien encuadernado lo de Extremadura. Larramendi se atreve a afirmar antes que el $\mathrm{Sr}$. don José. Mañana a las 6 sale. Pero recelo en mal día: pues dicen si mañana habrá la junta de jefes de Hacienda y ministros que tanto se habla× $(21 \cdot \mathrm{V}-31, \mathrm{III}, 176)$. 
reiterada versión del Eco del Comercio, las dificultades con que hubo de bregar Lamas Pardo le impidieron presentar el trabajo hasta 1833, a falta de las provincias exentas y la de Santander (52). Esto explicaría hasta cierto punto, la pasividad del gobierno a la hora de aprobar el proyecto que tenía disponible de división provincial, pero es preciso tener en cuenta también otras probables razones. Y es que la marcha de este negocio, como la de tantos otros en los años finales del Antiguo Régimen, refleja frecuentemente un exceso de prudencia ante lo que pudiera interpretarse como novedad o más exactamente, recordar las realizaciones de la época liberal. Como afirma Arias a cada paso, éste era el caso de los «arreglos» en los que entendía Lamas, como lo fue también el del proyectado ministerio del Interior, que deseaba vivamente Luis López Ballesteros.

A este respecto, parece interesante recordar que la oposición surgida en 1830 frente a la propuesta de López Ballesteros -la mitad exactamente de los consejeros de Estado, entre ellos Calomardejustificó su actitud no tanto con la descalificación del nuevo ministerio (casi todos confesaron la necesidad), sino más bien alegando la falta de oportunidad en su establecimiento (53). En efecto, tras la revolución de julio y las intentonas liberales en Tarifa y en los Pirineos, la media podía interpretarse quizás como una peligrosa concesión al adversario ideológico. Y fue precisamente en este contexto cuando Calomarde, el 16 de noviembre de 1830, aprovechó para explicar su propio criterio sobre el planteamiento de las reformas que patrocinaba:

«Juzgaba yo que el Gobierno, para tener un día ministerio del Interior debía ir organizando en particular los diferentes ramos que deben componerle, de tal manera que cuando llegase el momento de la reunión, se desprendiesen naturalmente de su antigua dependencia y tuviesen formas nuevas regulares que les uniesen entre sí.

A este fin empecé inmediatamente a trabajar en mi ministerio una nueva división de la península en provincias y partidos que está muy adelantada y en la que he consultado todo lo hecho hasta el día oyendo a los tribunales y justicias. Sobre las mismas bases se hace una distribución de audiencias y jueces letrados, a la que debe seguir la fijación del número de abogados, escribanos y demás curiales. Se ha

(52) Cfr. Eco del Comercio, 16 (16-V-34): «Sin embargo, el señor Lamas logró llevar su plan a punto de terminarse, y en 1833 lo entregó al Gobierno con el proyecto de división de 44 provincias en 439 corregimientos, quedando sólo por arreglar la de Santander».

(53) Vid. F. SUAREZ, aLa creación del Ministerio del Interior en España», en AHDE, XIX (19481949), 15-56; del mismo autor, la Introducción al Seminario de Historia Moderna, Documentos del reinado de Fernando VII. V. Pedro Sainz de Andino. Escritos (con un apéndice sobre la creación del Ministerio del Interior) (Pamplona, Universidad de Navarra/CSIC, 1969), III, 9-18. 
formado un expediente para averiguar la verdadera población del Reino y los diferentes métodos que se siguen en la composición de los ayuntamientos, a fin de mejorar esta institución más de lo que fue por la última Real Cédula que también promoví» (54).

Ahora bien: al menos en lo que se refiere a la división provincial, este prurito de avanzar sobre seguro y sin pérdida de la continuidad no se tradujo solamente en una cuestión de procedimiento, sino que llegó a afectar a los contenidos. Al ser desconocido el expediente de la división, resulta imposible obviamente, una valoración del proyecto en este sentido (así como fijar con exactitud su grado de dependencia respecto a la división del Trienio), pero no deja de ser ilustrativo confrontar las opiniones que menuderaron en la prensa de 1833 y 1834 sobre el tema; en todas ellas naturalmente se reitera la identidad del proyecto de la comisión de 1825 con el adoptado por Javier de Burgos.

En esa línea, el Boletín del 2 de septiembre de 1833 aconsejaba conservar las antiguas capitales de provincia y manteneer la entidad de los territorios históricos (55). En diciembre, una vez aprobada la ley, el mismo periódico afirmó: «en la división actual no se ha tocado a las cuatro provincias exentas, y se han consevado los límites de los antiguos reinos, reduciendo la operación a subdividir éstos en intendencias. Por defectos que pueda tener un trabajo de esta especie, delicado y embarazoso de suyo, y en el que se ha estado entendiendo desde 1825, siempre ofrecerá infinitas ventajas sobre la informe e irregular división actual (sic)» (56). En parecidos términos se expresó el Ateneo (57) y sobre lo mismo, aunque ya con el tono

(54) Memoria de F. T. Calomarde al rey (Madrid, 16-XI-30), en Seminario de Historia Moderna, o. c., Pedro Sainz de Andino (...), III, 217. No parece desde luego, que se diera carpetazo al proyecto: una R. O. de 1832 apara que a los corregidores y alcaldes mayores se les pague su asignación de los fondos de Propios, o por repartimiento vecinal» se estableció «con calidad de por ahora, y mientras Ilega a verificarse el arreglo de Provincias y Partidos, Tribunales y Juzgados en que se ocupa el Ministerio de Gracia y Justicia» (Col. Dec., 17-1-32, XVII, 6).

(55) Cfr. Boletín de Comercio, 84 (2-1X-33): «Los apreciables e importantes trabajos de dicha comisión, de que tenemos una circunstanciada noticia, están ya en poder del Ministerio del Fomento General del Reino, y no dudamos que tendrán una pronta aplicación, una vez que en ellos mismos están disueltas ciertas dificultades que podrían diferir su ejecución. Los temores sin duda fundados, que han podido asaltar al Gobierno, y que han paralizado sus más pronunciados deseos en negocio tan importante y trascendental, cesan a nuestro modo de ver dejando a las actuales capitales su capitalidad, dividiéndose en sí mismas las provincias de Cataluña, Aragón y Valencia sin incluir en una de ellas ningún pueblo o territorio de las otras, y verificándose lo mismo por lo que respecta a Galicia; y por último, que las provincias vascongadas y de Navarra no tengan ninguna alteración en sus límites».

(56) Idem, 113 (8-XII-33), «División de Provincias».

(57) Ateneo, 1 (5-1-34), 13: «División del Territorio: este interesante arreglo que tan imperiosamente reclamaba la buena administración, y la acción más pronta y enérgica del Gobierno estaba en verdad meditado por el benéfico monarca que lloramos (...). Las reformas 
acusadamente crítico que no dejaría en lo sucesivo, abundó el Eco del Comercio:

«Partióse del principio falso de que no convenía alterar las líneas divisorias de los antiguos reinos, para conservar las rivalidades provinciales que se supusieron origen de las heroicas empresas y nobles hazañas de los diversos pueblos peninsulares; $y$ en realidad era el objeto contemporizar con el espíritu de provincialismo, de excepciones y de privilegios, huyendo siempre de hacer homogéneo, poderoso y feliz al cuerpo social, que solamente dividido en intereses y rivalidades podía seguir subyugado al poder arbitrario. Huyóse también de una verdadera y general división, por no incidir en el sistema del gobierno intruso y del constitucional, que sin respeto a las carcomidas reliquias de las pasadas monarquías, demarcaron el distrito de cada provincia conforme a los términos naturales que ofrece el mapa físico del país.

De lo dicho se infiere claramente que el plan no fue dividir cómodamente la península, sino las grandes provincias ya existentes de antiguo; vicio que se sancionó en el año próximo pasado por el ministerio del señor Burgos, aprobando el proyecto mismo de 1825" (58).

En definitiva, ya fuera por atacar la política seguida por Zea y Burgos, ya por no dar motivos de alarma a la opinión conservadora, o simplemente porque se estimó así en términos objetivos, el hecho es que los periodistas de la Transición - los que se tomaron la molestia de comentar la reforma- se fijaron precisamente en aquellos aspectos de carácter más tradicional, donde era evidente la continuidad histórica con la estructura territorial del Antiguo Régimen: permanencia de las capitales preexistentes y conservación de los límites de los viejos reinos peninsulares. Una opinión desde luego, que merece tenerse en cuenta.

\section{Las ideas de Javier de Burgos sobre división provincial}

Muerto el rey en septiembre de 1833, el proyecto de división provincial volvió a cobrar actualidad. Se trataba en efecto, de algo necesario para desenvolver las reformas administrativas que consti-

deben ser tales que aparezcan conservadas las antiguas formas: y asi, esta nueva división del territorio es en la realidad una división de las antiguas provincias, conservando éstas sus mismos limites, la misma extensión y la prerrogativa de sus capitalesæ.

(58) Eco del Comercio, $16(16-\mathrm{V}-34)$; vid. en el mismo sentido la acrónica de Madrid» en 13 (13-V-34) y la primera entrega del aartículo remitidon por José de la Peña Aguayo en 31 (31-V34). 
tuían la parte principal del programa de Zea Bermúdez y hay lógica por tanto en el nombramiento de Javier de Burgos como ministro de Fomento en sustitución del conde de Ofalia, quien había pasado a formar parte del Consejo de Gobierno. Según el correspondiente decreto, fue elegido con la finalidad de proponer la división territorial y «en atención a sus especiales conocimientos en materias económicas» (59). La historiografía suele justificar esa fórmula con referencias a la famosa exposición (60) dirigida al rey en 1826 -donde indicaba la necesidad de establecer un ministerio de Fomento- pero lo cierto es que su curriculum explica con mayor claridad tal nombramiento: Burgos había sido subprefecto de Almería y corregidor interino de Granada durante la dominación francesa. Entre 1824 y 1827 desempeñó el cargo de comisionado de la real Hacienda en París, y posteriormente fue nombrado vocal de las juntas de Fomento, Aranceles y Tratados extranjeros, siempre en estrecha relación con López Ballesteros, el hombre a quien se atribuye la dirección efectiva de la tendencia moderanda durante estos años de supuesto oscurantismo. Pero, sobre todo, debe tenerse en cuenta que Burgos se había formado ideas detalladas, con bastante anterioridad a 1833, sobre todo lo referente a la división territorial y su necesidad.

En general, puede afirmarse que las ideas administrativas de Javier de Burgos aparecen casi en su completa madurez, en los numerosos artículos publicados en la Miscelánea de Comercio y en el Imparcial, los dos periódicos que dirigió entre 1819 y 1822 . No es cosa de pormenorizar aquí los rasgos ideológicos que sirvieron de base a esas ideas (61), aunque sí conviene recordar quizás, que Burgos se manifestó entonces como un representante muy caracterizado de la llustración en su facies más utilitaria. Confiaba, como era habitual en su tiempo, en el valor supremo de la Razón como medio de progreso y prosperidad, lo que le conduciría a sostener una concepción de carácter restrictivo sobre el acceso al poder político. Por otra parte, «gobernar —dirá- es sinónimo de hacer felices" (62), o lo que es lo mismo: la "conveniencia pública», impartir beneficios y prosperidad a los pueblos, constituye el título exclusivo de legitimidad de los gobiernos. Algo que en el último extremo, se correspondía plenamente con su idea de la Administración.

(59) Real Decreto de 21-X-33, citado por G. MARTINEZ DIEZ, art. cit., 584-585.

(60) Vid. Francisco Javier de Burgos, Exposición dirigida a S.M. Fernando VII desde Paris en 24 de enero de 1826, sobre los males que aquejan a España en aquella época (...) (Cádiz, 1834). 70. publicada también por Antonio MESA SEGURA, en Labor administrativa de Javier de Burgos (Madrid, IEAL, 1946); entre las biografias de Burgos, la mejor continúa siendo sin duda la que escribió Angel GonzÁleZ PALENCIA, aJavier de Burgos, humanista y politicon, en BRAE, XXII (1935), 203-228 y 343-387; XXIII (1936), 121-139 y 225-266.

(61) Me remito sobre este punto a mi reciente trabajo «La Miscelánea de Javier de Burgos. La prensa en el debate ideológico del Trienio Liberal», en Hispania Sacra, 41 (1989), en prensa.

(62) Miscelánea, 251(6-XI-21) 
Sin embargo, su experiencia personal bajo el gobierno absolutista, junto a la asimilación de las principales nociones de liberalismo doctrinario - que defendió desde las páginas de sus periódicos- le impidió caer en una interpretación rigurosamente totalitaria sobre el papel del Estado en la sociedad. Aborrecía por ejemplo «ese prurito de fabricar y comerciar, que ha sido siempre la manía de todos los gobiernos atrasados en la ciencia de la Administración» (63) y actuó, a menudo en situaciones críticas durante el Trienio, como un defensor ejemplar de las libertades individuales. La consecuencia de todo esto consiste a nuestros efectos; en un modo de gestión gubernativa que recuerda claramente la idea de Fomento en los términos en que ha sido definido por Jordana de Pozas (64). Debe hacerse también referencia entre los rasgos que definen el pensamiento administrativo de Burgos, a su adhesión a las modernas técnicas implantadas por Bonaparte. Es ocioso precisar si inició ese estudio allá por el 1800 como suponen algunos de sus biógrafos, si su interés se despertó en la época en que fue funcionario del gobierno Intruso, o bien durante la emigración de 1812 a 1817 . En cualquier caso, jámás pretendió ocultar el origen francés de tal conocimiento: "cuando se trata de Administración civil, allí es donde es necesario ir a estudiarla», escribió en el Imparcial (65).

Con semejantes coordenadas ideológicas, es fácil comprender que la división territorial no constituía para Burgos sino una pieza (eso sí, indispensable y preliminar) del sistema administrativo en el que depositaba tan grandes esperanzas. Era en efecto, la condición

(63) Idem, 528 (9-VIII-21).

164) Cfr. L. JoRdana de Pozas, aEnsayo de una teoria del Fomento en el Derecho Administrativon, en Homenaje al profesor Jornada de Pozas. I (Estudios de Administración local y general) (Madrid, IEAL, 1961), 480: «es una vía media entre la inhibición y el intervencionismo del Estado, que pretende conciliar la libertad con el bien común mediante la influencia indirecta sobre la voluntad del individuo para que quiera lo que conviene para la satisfacción de la necesidad de que se traten.

(65) Imparcial, 28 (7-X-21), 109; en 1820 (Miscelánea, 102, 10-VI-20). Burgos había ya insinuado su conocimiento de la legislación administrativa francesa: «Todos los hombres familiarizados con las materias de gobierno conocen la inmensa colección de 3.500 páginas enormes, en que por orden alfabético están reunidas hasta el año 1809 todas las leyes administrativas antiguas y modernas de uno de los principales países de Europan. Por otra parte, en una relación de libros que trajo consigo de Francia en 1827, se cuentan entre otros, el Bulletin des lois du Royaume de France (Paris, I. Royale, 1814-1826), 25 vols. en 8.०; Table generale par ordre alphabetique de matières, de lois, senatus-consulto, decrets (...) (París, I. Royale, 1816), 4 vols. en 8. ; L. RONDONnEAU, Collection generale des lois, decrets, etc. publicer depuis 1789 (...) (París, I. Royale, 1817-1819), 24 vols. en 8.\% M. LALOUTTE, Clasiffications des lois administratives depuis 1789 pasqu' an 1er abril 1814, precedè d'un essi sur les principes et les regles del' administration practique (París, V. H. Peronneai, 1817), 1 vol. en 4. ${ }^{\circ}$ Societte de gens de lettres, de savans, et d'artistes, Enciclopedie methodique. Jurisprudence, la police, et les municipalités (Paris, Stoupe, 1782-1791), 11 vols.; Charles-Jean BonNIN, Principes D'administration publique (París, 1812), 3 tomos en $8^{\circ}$ (se sigue en los títulos la grafía del ms.); hay que advertir, sin embargo, que en esta época (1827) Burgos se inclinaba mucho más hacia cuestiones de hacienda y finanzas, que a las propiamente administrativas (AHN, Cons., 11.301/164, Juez de imprentas, 1827). 
que hacía posible «la omnipresencia de la administración y generalizar sus beneficios" (66), de acuerdo con la expresión que gustaba de repetir y que se ha hecho un lugar común entre los administrativistas. Este aspecto - la definición del marco jurisdiccional de cada uno de los agentes de la cadena del poder - es sin duda el criterio que preside la reflexión de Burgos sobre la división provincial, al tiempo que explica su insistencia sobre la urgente necesidad de su formulación (67).

Si Burgos había ideado un proyecto de división en 1820 - como insinuaba- jamás lo publicó. En cambio, es posible conocer sus ideas con bastante detalle, a través de los artículos insertados en la Miscelánea y en el Imparcial. Conforme a la finalidad deseada - «extender al rincón más oscuro de cada distrito la acción benéfica de la administración”- (68) y de acuerdo con la doctrina más progresiva de su tiempo, aconsejó como base de la división la triple conjunción de población, extensión y límites naturales (69). Posteriormente se hizo eco de la necesidad de respetar «ciertos hábitos y aún ciertas preocupaciones» (70), pero lo cierto es que este factor - un mal necesario a su juicio- no se desarrolla de una manera consecuente en sus observaciones.

En resumen, era partidario -explicó en uno de los primeros números de la Miscelánea política- de una división territorial en cuatro grados, es decir, diez grandes distritos divididos en cuarenta provincias o departamentos, cada uno de los cuales se componía de cuatro subdelegaciones que constaban a su vez de cuatro partidos cada una. Se trata, por tanto, de una organización territorial presidida

(66) Miscelánea, 409 (12-IV-21); en parecidos términos, vid. el art.: «Sobre el proyecto de división territorial presentado a las Cortes», en el Imparcial, 22 (1-X-21), 86: «Nadie más que el autor de este artículo ha insistido sobre los beneficios inmensos que deben resultar de lo que creemos poder llamarse omnipotencia (sic, por omnipresencia, según advierte en p. 90) de la administración, o sea, de un sistema que haga sentir a un mismo tiempo y con igual eficacia en todos los puntos la acción tutelar del Gobierno».

(67) Las primeras manifestaciones de Burgos sobre la necesidad de formar la división territorial, se encuentran en la serie de artículos sobre $\alpha$ Estadística» que comenzó a publicar la Miscelánea el 14 de febrero de 1820 (núm. 46) -es decir, todavía bajo el gobierno absolutistay su contexto como puede suponerse tenía poco que ver con necesidades de indole política. Tras el cambio de Régimen, Burgos la señaló a las Cortes como algo previo a cualquier otra reforma (cfr. los núms. 146, 155, 210 y 226 entre otros), pero todavía en 1822 escribia amargamente: «Dos años van pasados y aún no hemos disfrutado de los beneficios que habría ya promovido indudablemente la división territorial, a habérsele dado desde luego toda la importancia que tenia» (Imparcial, 188, 15-III-22, p. 726).

(68) Miscelánea, $226(12-X-20)$.

(69) Vid. Idem, 54 (3-III-20): «Sobre Estadística; segundo artículo». Se trata del más extenso $y$ pormenorizado de los que escribió Burgos sobre estos criterios.

(70) Cfr. Imparcial, 22 (1-X-21), 86: «Se dirá quizá que siendo conveniente y aún necesario señalar en lo posible, límites naturales a las provincias, siéndolo igualmente proceder a esta operación en razón compuesta de la población y del espacio que ésta ocupa, y siéndolo por último respetar ciertos hábitos y aún ciertas preocupaciones cuyo origen se pierde en la noche de los siglos, pero que se han perpetuado hasta el día a favor de las diferencias de dialecto, de los usos $y$ aún de las leyes (...)». 
por el respeto más riguroso a la cadena de mando y, por supuesto, comprensiva de los servicios del Estado - y aún de la Iglesia- de manera integral. Aunque larga, la cita del propio Burgos merece la pena:

«En cada capital de provincia residiría un jefe político, un intendente, un obispo, un comandante militar y los correspondientes jueces de primera instancia. En cada capital de subdelegación residiría un subdelegado civil, que lo sería al mismo tiempo del jefe político y del intendente, un subdelegado eclesiástico con el título de arcipreste o vicario foráneo y un comandante de armas. En cada capital de partido residiría un juez de primera instancia y una junta de la clase de las que se llaman abadías en algunas diócesis, cuyo presidente sería el cura más antiguo, o el más condecorado de ellos si hubiese muchos (...). Suponiendo que el territorio de la monarquía española en el continente de Europa se dividiese en 40 provincias, cada cuatro de éstas podrán formar un distrito, en cuya capital residiría además el jefe político, del intendente y del comandante militar, un tribunal superior territorial y un comandante general. El cuidado de esta diócesis estaría a cargo de un arzobispo, de quien serían sufragáneos los tres obispos de las otras diócesis del distrito. Por este medio adquirirían todos los ramos del gobierno uniformidad y sencillez, se ocurriria prontamente a todas las necesidades, se evitarían o repararían muchas injusticias y se irían todos acostumbrando al espectáculo del orden y a la omnipresencia tutelar de la administración» (71).

Contra la impresión de rigidez en esta descripción, hay que decir que Burgos era bastante consciente de la provisionalidad de su proyecto, como de cualquier otro que pudiera formarse. Una buena división era resultado de la experiencia y de mapas exactos, lo que se traducía en una demora inaceptable en su opinión, para un negocio de tanta importancia. De ahí el carácter acomodaticio, la facilidad de adaptación de su pensamiento al coetáneo proyecto de Bouzá.

No en todos sus aspectos, desde luego. El número de cuarenta provincias «una más, una menos», estaba prestigiado por las

(71) Miscelánea, 90 (26-V-20); idéntica integración de funciones -judicial, religiosa, administrativa, militar - se encuentra en el proyecto contenido en el Reglamento para la Iglesia de España, de Llorente (30-V-1808), bien que en este caso, se trata de una división de dos grados: 15 grandes provincias divididas en 65 departamentos (cfr. G. Dufour, art. cit., 12-13); por el contrario, en el segundo proyecto de Llorente (el analizado por Melón), «se asignaba a cada departamento una universidad, una audiencia y una diócesis» (cfr. J. Mercaoer, o. c., 231). 
divisiones de 1810 y 1813 (39 respectivamente) (72) y por la experiencia administrativa francesa, ya que este país, con una población de 26 millones y medio de habitantes, se hallaba dividido en 84 departamentos (73). Habida cuenta de que las circunscripciones de 300.000 almas se consideraban idóneas para el gobierno provincial, y que la población de España se suponía cercano a los doce millones. Burgos estimaba desproporcionado $-y$ por tanto antieconómico- el proyecto de 51 provincias de F. Bauzá, modificado por la comisión de Cortes. La alternativa, cuarenta provincias pero divididas en subdelegaciones para conservar el vigor de la acción administrativa, fue por tanto la opción que sostuvo el Imparcial con mayor interés y continuidad entre todas las que expuso sobre esta materia (74).

Por el contrario, Burgos parece aceptar con pocas modificaciones otros rasgos del proyecto de 1821 . Por ejemplo, clasificó también a las provincias en tres categorías (siete de primera, diez de segunda y 22 de tercera, aparte de Madrid) (75), pero usando como criterio la importancia socioeconómica de las capitales y no - como la comisión de Cortes - el peso demográfico provincial, lo que conducía a paradojas que supo explotar con habilidad: «Pero, ¿qué mucho si están en la misma el triste e insalubre lugar de Chinchilla que tiene 1.200 habitantes, y la rica y opulenta Palma, emporio de las Baleares, que habitan 70.000 individuos? ¿Qué mucho si Valladolid, verdadera capital de Castilla la Vieja y residencia del primer tribunal superior de la monarquía, está en la misma clase que Huelva, conocida tan sólo de poquísimas personas, y esto sólo por el paso de los atunes?» (76).

Tampoco hizo gala de una gran originalidad en la elección de las capitales. Las únicas variantes respecto al proyecto de Bauzá consisten en cierta preferencia por Mérida y Albacete frente a Badajoz y Chinchilla; coincide con éste en la designación de Vigo por Pontevedra (77).

(72) Cfr. Imparcial, 22 (1-X-21), 85; también el proyecto de Amorós - antecedente inmediato de la división de 1810 según Dufour - fijaba el número de departamentos en 38, de acuerdo con los criterios de población, extensión y límites naturales (aunque no mencionaba explícitamente los dos últimos como tales) (vid. «División nueva de la España en departamentos (...) m, en G. DUfOUR, art. cit., 19 y 20 especialmente).

(73) Cfr. Imparcial, 28 (7-X-21), 109

(74) IDem, 22 (1-X-21), 86; parece influido de manera muy directa en este aspecto por el mencionado proyecto de Amorós, quien sugiere la cita de 300.000 almas como base para los departamentos, y la idea de las subprefecturas (cfr. «División nueva de la España en departamentos (...)», en G. Dufour, art. cit., 20-21).

(75) Cfr. Imparcial, 23 (2-X-21), 90; de primera clase: Cádiz, Sevilla, Málaga, Granada, Valencia, Barcelona y Mallorca. De segunda: Coruña, Valladolid, Salamanca, Toledo, Cuenca, Córdoba, Alicante, Jaén, Murcia y Canarias. aMadrid continuaría formando como hoy una clase particular, y las otras 22 provincias que faltan para completar el número de 40 de nuestro plan serían de tercera clase».

(76) Idem, $26(5-X-21), 192$

(77) Vid. especialmente Imparcial, 25 (4-X-21), 97-98. 
Hay que advertir que en ningún momento publicó una relación completa de sus 40 provincias. Todas las que menciona expresamente en sus artículos -34 en total-se encuentran también en la división de 1822 y, por tanto, en la de 1833. Entre las que desecha hasta las 52 - número aprobado finalmente por las Cortes- estaban Castellón, Calatayud, Huelva, Játiva, Soria, Teruel y Villafranca; es probable que contemplara también - como Bauzá- la refundición de las tres provincias vascas.

En cuanto a denominaciones, manifiesta un transaccionismo significativo. No oculta su preferencia por la nomenclatura geográfica, al modo francés, si bien era demasiado realista para no reconocer que «esta imitación produciría entre nosotros una confusión notable. visto el número inmenso de personas que no saben hacia qué parte caen el Ter, el Sil ni otros ríos que deberían quizá dar su nombre a departamentos» (78). En cualquier caso, debían eliminarse los nombres de los antiguos reinos, motivo de provincialismo, esto es, «de divergencias en las opiniones y aún de rivalidades y odios». Evidentemente, se trataba de algo que chocaba en su concepto, con la unidad y la concordia nacional, dos de los factores determinantes -entre otros- del valor social por antonomasia, la prosperidad. En su lugar, insinúa la denominación en función de las respectivas capitales -el criterio de Amorós- que se seguiría también en la división de 1822 (79).

Por último, la cuestión de los límites. Es muy poco probable que Burgos tuviera ideas precisas sobre el contorno de cada una de las 40 provincias que sugiere. De hecho, describe con detalle Granada y Almería (que tenía motivos para conocer bien) y aporta únicamente datos aislados para otras provincias. Aparte reflejar aquí cierta originalidad respecto a las restantes divisiones conocidas, se revela una especial sensibilidad hacia el criterio topográfico, es decir, un respeto exagerado por los accidentes del terreno, ríos especialmente: «En nuestro dictamen Tarragona no debía pasar a la derecha del Ebro, y el que se hable catalán en Ulldecona y en San Carlos, no es una razón para saltar un límite que parece puesto a propósito para dividir aquella provincia» (80). Algo muy coherente, en efecto, con la admiración ilustrada por la Naturaleza.

(78) Idem, 26 (5-X-21), 102; critica especialmente el criterio ecléctico - nombres tomados tanto de capitales como de regiones para designar a las nuevas provincias- propuesto por Larramendi y Bauzá.

(79) Idem; «una de las ventajas de la división territorial es la de confundir en una denominación genérica y nacional todas las denominaciones provinciales»; a su vez, Amorós escribio: «En estos momentos se ha visto el mal que ha producido que hubiese tanto Aragoneses, Andaluces, Vizcaínos, Castellanos y Valencianos y tan pocos españoles verdaderos» («División nueva de la España en departamentos (...) ) en G. Dufour, art. cit., 19).

(80) Imparcial, 25 (4-X-21), 98; sobre la división territorial de Granada y Almería, vid. Miscelánea, 438 (11-V-21), 490 (2-VII-21) e Imparcial, 24 (3-X-21), 94. 
En resumen, las ideas formuladas por Javier de Burgos entre 1820 y 1822, parecen el resultado de una reflexión personal sobre dos corrientes de pensamiento bien diferenciadas. Manifiestan, en primer lugar, una fuerte influencia de la división de 1810 (y quizás también de sus trabajos preliminares, de Llorente y Amoros) en cuanto a los planteamientos generales. Indicativo del alcance de esa influencia podría ser la valoración que hizo de la división de obispados formada entonces por Llorente: «en ella, los principios son en general excelentes, aunque no lo es en nuestro dictamen la aplicación» (81). De hecho, Burgos difiere bastante de la división josefina en cuanto a la elección de las capitales y -por lo que sabemos - la configuración de las provincias, pero se advierte la misma preferencia por el esquema aproximado de 40 demarcaciones (resultado según parece, de la relación extensión-población, desde un enfoque administrativo), así como por el criterio de límites naturales. $Y$ naturalmente, asume la estructura de agrupaciones de provincias formada en 1811 (que Burgos llama distritos) y la de subprefecturas, pues no son otra cosa las subdelegaciones que tanto encomió.

Es también clara la adaptación de sus ideas, ya en 1821, al coetáneo proyecto de Bauzá y Larramendi remodelado por la comisión de Cortes, que comentó ampliamente en el Imparcial. No se explica de otra manera la conformidad de todas las provincias que propone, y de la mayor parte de las capitales con dicho proyecto, si bien, purgado de sus disposiciones menos viables: la existencia de las provincias de Játiva, Calatayud, Villafranca, etc., o la capitalidad de Chinchilla (82). Como se echa de ver fácilmente, cierto número de rasgos aquí indicados pasaron de una forma $u$ otra a la división de 1833. Por el contrario, es importante hacer notar que otros aspectos de esta división, precisamente aquellos en los que suele señalarse el sentido "histórico" como factor aglutinante, no son explicables desde la perspectiva de los proyectos del Trienio o los anteriores, ni a partir de los artículos de Burgos en la Miscelánea y el Imparcial. En cualquier caso, las preferencias del futuro ministro de Fomento no constituyeron, como veremos, un elemento ajeno a la definitiva división provincial.

(81) Miscelánea, 181 (28-VIII-20), «otra nueva conversación entre Cándido y Prudencio. escrita por el fecundo Llorente, relativa a la división de obispados».

(82) vid. Imparcial, 27 (6-X-21), 106, la valoración de Burgos sobre el proyecto presentado a las Cortes en 1821: «Por dicha la declaración de haber lugar a deliberar sobre la totalidad del proyecto, no quiere decir otra cosa, sino que se reconoce la necesidad de una división, y que la presentada está en general bien hecha, aún cuando en los pormenores haya mucho que corregir. Así, los amantes del bien no han debido inquietarse por aquella declaración preliminar, pues en la discusión de los artículos se podrían reformar los errores y los vicios. Tampoco han debido inquietarse de que se haya rehusado fijar de antemano el número de provincias (...) \$o. 


\section{La culminación de los trabajos después de la muerte del rey}

Consecuente con su trayectoria, Burgos actuó con una gran celeridad sobre toda esta cuestión. El 23 de octubre de 1833, dos días después de su nombramiento y al parecer sin haberlo consultado siquiera con el resto del gabinete, obtuvo el decreto de creación de los subdelegados de Fomento. Como en éste se contempla también la figura del subdelegado subalterno a razón de «dos o tres" por provincia (83), es claro que pensaba aún en los términos de su antiguo esquema, es decir, grandes provincias subdivididas para su mejor gobierno.

Sin embargo, en pocos días hubo un cambio de orientación sobre este punto, ya que el 29 de octubre se presentó a sus colegas -es la primera intervención de Burgos recogida por las Actas del Consejoel proyecto de división territorial formado por la comisión que se nombró en 1825. Los ministros lo aprobaron sin dificultad $y$ acordaron en consecuencia, enviar «este proyecto de límites de las provincias, con el informe de la comisión y el mapa que le acompaña, al Consejo de Gobierno» (84).

Consta por el oficio de remisión (1 de noviembre) que el ministro introdujo de su mano alguna modificación. Desconocemos en qué consistió - aparte, obviamente, de las menciones a los subdelegadospero como indica el mismo Burgos, debió ser de poca entidad y desde luego, no afectaba a los límites provinciales perfilados en los trabajos que se realizaron en la década anterior (85). Este «Proyecto rectificado» enviado al Consejo de Gobierno coincide sustancialmente con el

(83) Cfr. Col Dec., XVIII, 264-265, «Real decreto mandando establecer Subdelegados de Fomento, del modo que se expresan (23-X-33).

(84) Actas C.M. (29-X-33), 342-343: «formado por la comisión nombrada al efecto el 16 de diciembre de 1825 , con presencia de los diferentes trabajos que había preparados y de lo que han manifestado las Audiencias y Chancillerías y representado algunos pueblos a consecuencia de las Reales Ordenes e instrucciones comunicadas en 22 y 31 de marzo de 1829 para proceder al arreglo de corregimientosn.

(85) Cfr. AHN, Estado, 885/3: «Exmo. Señor: El Consejo de Señores ministros tomó en consideración en la sesión que celebró el 29 del mes próximo pasado, el proyecto de ley para la división de provincias, el de límites de las mismas, y la exposición de los motivos que se tuvieron presentes para fijar éstos por la comisión creada al efecto en 16 de diciembre de 1825; y habiendo yo expuesto de palabra que el mencionado proyecto de ley me parecía en lo sustancial fundado y juicioso, pero que las circunstancias que han sobrevenido a su redacción, y otras consideraciones que desenvolvi, aconsejaban hacer en él algunas variaciones por no ser consecuentes muchas disposiciones a algunas de las últimamente adoptadas por S.M. la Reina Gobernadora, acordó el Consejo proponer a S.M. pasarlo al de Gobierno para que manifestase sobre todo su parecer. Conformándose con éste S.M. ha tenido a bien mandar se remitan al Consejo de Gobierno tanto el enunciado proyecto de ley ligeramente modificado, como el de límites de las provincias con el informe de la comisión, y el mapa que le acompaña, en que se demuestra la nueva división de ellas, a fin de que haciéndose cargo de la gravedad e importancia del asunto, de lo urgente que es su resolución para que cuanto antes puedan verse realizadas las benéficas miras que S.M. se ha propuesto al acordar el establecimiento de los subdelegados de fomento, y para que se ejecuten otras que S.M. tiene concebidas, consulte a la mayor brevedad a S.M. manifestando cuanto se le ofrezca sobre el particular. De Real orden lo digo a V.E. con 
decreto publicado el 30 de noviembre; esto es, consta de 49 provincias agrupadas en los correspondientes territorios históricos y que reciben - salvo Navarra y las tres provincias vascas- la denominación de sus capitales. Una única variante: la provincia y capitalidad de Barbastro en lugar de Huesca, de cuya posterior sustitución no da razón documento alguno de este expediente (86).

No parece que se trate de una conversión ideológica por parte de Burgos al pensamiento de la comisión de 1825. Por el contrario, la urgencia de la situación, el carácter de provisionalidad que se atribuía al decreto (art. 6) y quizás, el sentido transaccionista que era propio del liberalismo doctrinario, explican bien que el ministro sacrificara algunos aspectos de su preferencia: el criterio geográfico frente al histórico para la formación de los límites, o el modelo de 40 provincias por el de 49 . Sin embargo, el proyecto conservaba aún las dos principales manifestaciones de su ideario administrativo en esta materia: la figura de los subdelegados de provincia y distrito (arts. 6 y 7), y el carácter comprensivo de los diferentes servicios del Estado o escala provincial (art. 4).

Ahora bien, el Consejo de Gobierno -la peculiar institución establecida en el testamento de Fernando VII- estuvo a punto de echar a pique ambas ideas. El 8 de noviembre manifestó con mucha prevención, carecer de datos para consultar, principalmente por lo que atañía a los subdelegados (87). Burgos se apresuró a enviar toda la documentación disponible, insistiendo en la urgencia del proyecto - «que S.M. quiere ver planteado inmediatamente»- y en último extremo, en el carácter disociable de la división provincial respecto al establecimiento y atribuciones de los agentes de Fomento (88). En

inclusión de los documentos expresados, a fin de que se sirva dar cuenta de todo al Consejo de Gobierno. Dios guarde a V.E. muchos años. Madrid, 1 de noviembre de 1833. Javier de Burgos Secretario del Consejo de Gobierno.

(86) Ibidem, «Proyecto de ley para la división de provincias, rectificado»; vid. también Col. Dec., XVIII, 289 y ss., «Real decreto mandado hacer la División territorial de Provincias del modo que se contiene en seguida» (30-XI-33). Aparte de la mencionada inclusión de Barbastro, luego Huesca, las diferencias entre ambos textos se reducen a: 1) algunos guros estilisticos que proporcionan mayor precisión; por ejemplo, en el art. $4 .^{\circ}$ del proyecto se afirma que la división será «común a todos los ramos del servicio del Estado», mientras en el decreto definitivo «que se arreglarán a ella las demarcaciones militares, judiciales y de haciendan; 2) Los diferentes reinos andaluces, que se mencionaban de manera dispersa en un orden alfabético general, se reagruparán en el decreto (art. 2.); 3) Se añade un último párrafo al artículo $3 .{ }^{\circ}$ del decreto, relativo a limites fronterizos con Francia y Portugal.

(87) Cfr. Actas C.M. (10-XI-33), 357. Los dictámenes del Consejo de Gobierno pueden seguirse también en la colección de sus actas (AHN, Estado, 906).

(88) Cfr. AHN, Estado, 885/3, J. Burgos al secretario del Consejo de Gobierno (11-XI-33); remite un proyecto de decreto para el establecimiento de las subdelegaciones; estados de cuentas de las subdelegaciones de policía y previsión de las de fomento; reflexiones sobre lo mismo; decretos y órdenes expedidas por Fomento desde el nombramiento de Burgos. Ofrecía también «una instrucción formada para que sirva de guía a los subdelegados en el ejercicio de su vastas e importantes funciones». Con fecha de 12-XI-33 completa la colección de decretos publicados por Fomento. 
consecuencia, el Consejo contestó el día 20 sobre la división y el 23, más pormenorizadamente, sobre la cuestión de las subdelegaciones: se manifestaba a favor de lo primero, si bien, limitándola por ahora a los efectos puramente administrativos (89) y encargando la formación de planos topográficops, etc., a los intendentes en vez de a los pretendidos subdelegados, como habían propuesto los ministros. Por el contrario, su juicio sobre los subdelegados, su planta y atribuciones, era muy negativo -incluso despectivo - tanto en lo que atañía a la formulación del proyecto ("es una memoria para leer en una sociedad de literatos", dijo de la Instrucción) como a los conceptos de fondo:

«El proyecto y sus adminículos respiran cierto aire de tutoría de los intereses generales. El Fomento, bien entendido, reconoce por única base la remoción de obstáculos: operación por su naturaleza lenta, y que conviene casi siempre emplear indirectamente para que sea provechosa» (90).

Por supuesto, este dictamen no gustó en el Consejo de ministros, pero no era cosa de enfrentarse abiertamente con el de Gobierno. Fue objeto de una discusión prolongada - sesiones de 26 y 29 de noviembre- en el transcurso de la cual, Burgos «entró en el examen y fundamentos de esta opinión; mostró los inconvenientes que se seguirían de adoptarla; probó la contradicción que existía entre la aprobación de la División Territorial limitada a la parte administrativa y la no aprobación del establecimiento de las subdelegaciones de Fomento; y expuso otra multitud de consideraciones que en resumen indicó en una exposición a S.M., que leyó en seguida, y cuyas conclusiones eran que la Reina Gobernadora se sirviese aprobar el proyecto de División Territorial, el de establecimiento de subdelegaciones de Fomento y una Instrucción para los agentes que hubiesen de servirlas». Convenció a sus colegas. Estos confirmaron su adhesión a las propuestas y acordaron que el ministro de Estado solicitara la aprobación de la reina Gobernadora sin perjuicio de que el mismo Burgos le diera cuenta más circunstanciada (91).

Lo que sigue es conocido. El 30 de noviembre se publicaron los decretos sobre división territorial y subdelegados, junto a la corres-

(89) Ibidem, minuta del consejero Nicolás María Garelly para el dictamen sobre División territorial; sobre el punto en cuestión, escribió: «que el artículo $4 .^{\circ}$ por el cual se dispone ser "extensiva la división a todos los ramos del servicio del Estado", se redacte diciendo: esta división se entiende limitada por ahora al orden administrativo, sin perjuicio de hacerla extensiva a los demás ramos del Estado, luego que se reúnan los datos necesarios para que tengan lugar en cada uno de ellos, y se remuevan legalmente los obstáculos que pudiesen arredrarla en algunos».

(90) Ibidem, «Análisis del Proyecto de Decreto sobre establecimiento de subdelegaciones de Fomento y documentos que le acompañan» (el segundo texto entrecomillado corresponde a la Observación general preliminar).

(91) Actas C.M. (29-XI-33), 372-373. 
pondiente Instrucción, lo que era -de 'momento- un triunfo completo de los puntos de vista sostenidos por Burgos, sin más concesiones que la reducción del número de subdelegados de partido (o subalternos) que deberían ser nombrados más adelante. Algo lógico, puesto que se había adoptado un esquema de provincias territorialmente más reducidas que en el modelo propuesto al principio por el ministro (92). Sin embargo, a esas alturas el gabinete se había creado demasiados enemigos -el Consejo de Gobierno entre ellos-como para sobrevivir el tiempo necesario a la implantación de la reforma. Los subdelegados de provincia fueron investidos en efecto de la correspondiente dignidad, y se dictaron disposiciones minuciosas para su toma de posesión (93), pero en algunos lugares, especialmente en Cataluña, hubo resistencias que hicieron ilusorio el cumplimiento de lo que se esperaba de ellos. El general Llauder, por ejemplo, se negó a recibir el juramento de Serafín Chavier, afirmando «que tenía que exponer a S.M. los grandes inconvenientes que ofrecían estas innovaciones». Su exposición -la de 28 de diciembrese recibió, pero no fue obstáculo para que se le enviaran órdenes bastante perentorias a este respecto (94). Aunque Llauder prometió efectuarlo, el 13 de enero, día previsto para la toma de posesión dejó plantados a dos subdelegados «bajo el pretexto de pasar revista a un cuerpo». Para colmo, la noche anterior había habido una asonada en Barcelona en la que se gritó «fuera ministerio, fuera Fomento», por lo que el general se manifestaba partidario de diferir la instalación "hasta que mejorarsen las circunstancias», dictamen que encontró apoyo en los tres subdelegados catalanes, Antonio Barata, Serafín Chavier y Joaquín Rey (95). En suma, la prudencia del Gobierno en evitar actos como éste, resumía Burgos años después, impidió

(92) Cfr. Col. Dec., XVIII, 336, «Real decreto disponiendo los subdelegados y demás empleados de Fomento que ha de haber en las Provincias, e Instrucción que acompaña y deberán aquellos observar» (30-XI-33): «Habiéndose reducido notablemente la extensión de las provincias de resultas de la nueva división, se modificará con arreglo a esta circunstancia la disposición del mencionado decreto de 23 de octubre, que prevé haya dos o tres Subdelegados de Partido en cada una, y sólo se establecerán uno o dos en las de mayor extensión e importancia (...) (art. 3. ${ }^{\circ}$ ). Pero debe advertirse que esta medida no supone una rectificación en el pensamiento de Burgos, quien años después continuaba abogando por el establecimiento de los subdelegados subalternos (vid. „/deas de Administración. Capítulo tercero. De los administradores de distrito", en Alhambra, IV/7, 14-II-41, 73-75).

(93) Vid. Col. Dec., XVIII, 393, «Real decreto declarando la categoría de los Subdelegados de Fomento y el uniforme de todos los empleados de este ramo» (22-XII-33); ibidem, 453-459, «Real orden sobre jura, establecimiento y gobierno de los Subdelegados de Fomento» (29-XII-33); vid. también Actas C.M. (28-XII-33), 410: Burgos leyó una minuta de circular a los capitanes generales para que con arreglo al decreto del 30 de noviembre, entregasen el negociado de policía y sus dependencias; asimismo, un articulo «que se acompaña a la Instrucción». encargando a los Subdelegados escrupulosidad en la transmisión de noticias de interés para la seguridad de reino, a los capitanes generales.

(94) Cfr. Actas C.M. (6-1-34), 4.

(95) Ibidem (21-1-34), 25. 
organizar entonces por completo la administración provincial (96). Su propia salida del ministerio no mucho después - a mediados de abril de 1834 - determinaría el fin de los subdelegados de partido que había proyectado, en tanto que los de provincia pasaron a denominarse jefes políticos y más tarde gobernadores.

Burgos fue algo más afortunado en cuanto a la presentación de integrar la totalidad de los servicios del Estado en la estructura provincial, puesto que siendo aún ministro tuvo conocimiento del proyecto de la nueva demarcación militar (97), así como de los primeros pasos habidos para poner en planta la judicial (98). La nueva división de tribunales superiores fue publicada el 2 de febrero de 1834 y se fundamentó, a lo que parece, en los trabajos realizados durante el reinado anterior (99). A su vez, la de partidos judiciales cobró especial urgencia cuando se acordó la convocatoria de Cortes del Estatuto Real. En el mismo mes de febrero se había nombrado una comisión para formarla, pero con las prisas, explica el Eco del Comercio, ésta no hizo otra cosa que reproducir el trabajo de Lamas Pardo, pasando por alto la mayor parte de los defectos observados (100). El mismo principio guió la actuación de los ministros, que remitieron el proyecto el 13 de abril - tres días después de la publicación del Estatuto- al Consejo de Gobierno. Este, comprensivo, «no encuentra reparo en que se apruebe la división según viene propuesta por la comisión, sin perjuicio de hacer después las correspondientes modificaciones, cuando las autoridades de las respectivas provincias manifiesten que efectivamente hay defectos que enmendar o mejoras que hacer » (101). Ahora bien, como Lamas, por las razones que fueran, no había incluido en su proyecto la división de partidos de las provincias vascongadas y Navarra (102), la

(96) Vid. aldeas de Administración. Capítulo segundo. De los jefes políticos», en Alhambra, IV/6 (7-II-41), 62.

(97) Cfr. Actas C.M. (23-1-34), 30-31.

(98) Cfr. AHN, Estado, 896/6, Juan Gualberto González remite al Consejo de Gobierno el proyecto de división de provincias entre las actuales audiencias y chancillerías para consulta (24. XII-33); contestación en 3-I-34.

(99) Vid. AHN, Cons., 3951/2, «Real Cédula de S.M. y Señores del Consejo por la que se manda uniformar los Tribunales Superiores y manda observar la nueva división y atribuciones del territorio de los mismos, que se expresa; creándose dos reales audiencias en Burgos y Albacete (2-11-34): «Después de examinados los planos, estados, memorias y proyectos que con tan importante objeto se trabajaron de orden del señor Rey don Fernando VII (que está en gloria) por una comisión de magistrados y otras personas celosas del bien público y versados en la materia» (...).

(100) Cfr. Eco del Comercio, 16 (16-V-34): «¿Cómo consentir en el reinado de Isabel que subsistiesen propuestas para cabezas de partidos poblaciones que no tenian otros méritos que un número considerable de realistas, un fanatismo atroz, un padrino adicto a las esperanzas de don Carlos? Con todo, la excesiva premura no ha debido permitir que se corrijan muchos errores de esta clase, y es de esperar que los trabajos sucesivos vayan perfeccionando una obra, dedicada de suyo, viciada desde su origen y llena todavia de numerosas faltas e imperfecciones».

(101) AHN, Estado, 906, minuta del conde de Ofalia anexa al acta núm. 62 (18-IV-34).

(102) Tampoco Santander, según el citado artículo del Eco, 16 (16-V-34). 
"comisión mixta de división territorial» al servicio del gobierno hubo de afrontar el trabajo. Por fin, estuvo preparada y se envió al Consejo a finales de junio. Una vez más, el supremo organismo consultivo opinó que «se haya arreglada» si bien, respondiendo a una cuestión muy concreta planteada por Garelly, juzgaba que convendría «suspender la aprobación hasta la pacificación» de esas provincias (103). $Y$ es que, como se había observado tantas veces durante el largo proceso de la organización territorial, era temerario cuando menos, ofender los sentimientos de una parte del país.

\section{Epilogo}

A la vista de cuanto va expuesto, parece considerable la dificultad para atribuir, en exclusiva, la responsabilidad de la división de 1833 a un único equipo de hombres o a una corriente ideológica aislada. Por el contrario, da más bien la impresión de consistir en el resultado de un proceso acumulativo de las diferentes tentativas efectuadas en el transcurso - al menos- del primer tercio del siglo XIX. Como es sabido, la influencia de los trabajos del período constitucional fue decisiva, de acuerdo con las conclusiones proporcionadas por el método comparativo. Ahora bien, tal influencia se canalizó a través de la elaboración de la comisión de 1825 (en concreto, la presencia de J. A. Larramendi explica bien la conexión) y no de una manera directa. Por lo demás, ya se ha visto que el ministro Burgos (que interpretó de acuerdo con sus personales criterios las aportaciones de la década) poseía un buen conocimiento de lo realizado en el Trienio. En suma, también en lo referente a la reforma territorial, parece aplicable la observación de F. Suárez sobre la "permeabilidad» que se observa entre las sucesivas etapas de plena soberanía real y las liberales (104).

La expresión más evidente - pero no la única- de la influencia del proyecto liberal sobre la división de 1833 consiste en la elección del esquema de 49 provincias, dependiente de las 52 contempladas en el decreto de 1822. Sin excluir los objetivos de índole administrativa, el pensamiento constitucional doceañista concibe la estructura territorial con una finalidad principalmente "política", es decir, en cuanto cauce de la soberanía nacional. Una división uniforme era

(103) AHN, Estado, 897/28, Garelly (ahora ministro de Gracia y Justicia, antes vocal del Consejo de Gobierno) al secretario del Consejo de Gobierno (26-VI-34) y minuta de resolución (4VII-34).

(104) Cfr. F. SuARez, Notas sobre la Administración en la época de Fernando VII (separata de Actas del I Simposio de historia de la Administración) (Madrid, IEA, 1970), 11: «Si comenzamos a hacer calas a lo largo de los años de reinado observando, sobre todo, el aspecto de reformas administrativas, se encuentran indicios suficientes no sólo para afirmar un cierto espíritu de reforma, sino también una cierta permeabilidad entre las distintas etapas». 
congruente con la necesaria igualdad legal de todos los españoles, así como el supuesto de sus operaciones consecuentes: sistema electoral, contribuciones, etc. Por otra parte, el individualismo de raíz roussouniana implícito en la Constitución de 1812 requería la existencia del menor número de instancias gubernativas interpuestas entre los ciudadanos y la suprema autoridad. Consecuencia de todo ello era la necesidad, en la práctica, de diseñar circunscripciones más reducidas y simples, por ejemplo, que en la división josefina de 1810.

La falta de documentación primaria se traduce en una dificultad insoslayable para estimar en su justa medida, la aportación de los trabajos realizados durante la última etapa del reinado de Fernando VII. Sin embargo, existen datos suficientes como para poder adscribir a esta orientación una serie de rasgos que prácticamente todos los autores desde Amando Melón, han puesto de relieve en la división de 1833 (105). Se trata precisamente de aquellos que denotan una mayor preocupación por evitar la ruptura con el pasado: la configuración definitiva de los límites provinciales, la conservación de la entidad - siquiera nominal- de los antiguos reinos, o incluso de las capitales preexistentes. Sin embargo, debe tenerse cierta cautela a la hora de valorar la importancia real del «principio histórico" en el proyecto de futuro que se perfilaba en 1833. Luego volveremos sobre ello.

Tampoco parece desdeñable la intervención personal del ministro de Fomento en este proceso. Más que por la originalidad de pensamiento, Javier de Burgos se caracterizó por su capacidad de asimiliar y llevar a la práctica las teorías en boga de su tiempo; frecuentemente, podría añadirse, con una osadía y una suficiencia que irritó a sus coetáneos. Desde este punto de vista, su aportación más genuina consistió en la impronta de un peculiar enfoque -la finalidad administrativa - que era resultado de la herencia ilustrada, de la recepción de la metodología francesa $-y$ afrancesada, si se quiere-y su interpretación del liberalismo doctrinario. En concreto, a sus ideas parece deberse el impulso definitivo a la sistematización de los servicios del Estado en la estructura provincial (todavía vacilante en el proyecto liberal) y muy especialmente, la consolidación del concepto de provincia como ámbito jurisdiccional de los agentes delegados del Poder: uniformidad y centralización, en suma.

La conjunción de estos tres elementos configuradores, tan dispares en su origen (y que a grandes rasgos podrían adscribirse a las tres principales corrientes de pensamiento político en el siglo XIX español), parece relacionarse con la permanencia inalterada de dicha

(105) Sin embargo, pocos han sentido la necesidad de explicar su origen de una manera coherente. Entre ellos, I. Olábarri justifica ese arelativo historicismo» (cfr. art. cit., 86 y n.) vinculándolo al «concepto de pueblo o nación» propio del liberalismo doctrinario. 
división en el transcurso del siglo calificado con razón, de la inestabilidad. No sólo - como afirmó Calero- porque su carácter instrumental la hacía válida para servir a políticas de diferente signo, sino también porque las "concesiones a la Historia» facilitaron probablemente su implantación. Como se vio, ésta era la solución apuntada en un principio por el Boletín de Comercio, en tanto que las resistencias conocidas a fines de 1833 se oponían a un aspecto muy concreto de la reforma -el establecimiento de los subdelegados- $y$ no propiamente la configuración territorial.

Por último, desde la perspectiva de esta triple confluencia, es posible aún una aproximación a la división de 1833 en cuanto expresión del nacionalismo unitario, o - según la formulación de $\mathrm{I}$. Olábarri-su conexión causal con los «nacionalismos periféricos». Si por división provincial se apunta a la cuestión de los límites territoriales, es forzoso concluir, paradójicamente, que no solamente no dañó, sino que aún contribuyó a preservar la peculiaridad regional. Pero por división provincial no suele entenderse simplemente eso. Como instrumento de centralización, que comporta la existencia de una estructura radial de poder y unas pautas de uniformidad, iba cuando menos a interferir el desarrollo armónico de dicha peculiaridad. $Y$ en ese sentido mucho más propio, su influencia respecto al surgimiento $y$ las actitudes manifestadas por los nacionalismos antagónicos, no puede ciertamente extrañar. 
REALA-1990, núm. 247. MORAN, MANUEL. LA DIVISION TERRITORIAL EN ESPAÑA: 1825-1833.

REALA-1990, núm. 247. MORAN, MANUEL. LA DIVISION TERRITORIAL EN ESPAÑA: 1825-1833. 
REALA-1990, núm. 247. MORAN, MANUEL. LA DIVISION TERRITORIAL EN ESPAÑA: 1825-1833.

REALA-1990, núm. 247. MORAN, MANUEL. LA DIVISION TERRITORIAL EN ESPAÑA: 1825-1833. 